\title{
Turbulence kinetic energy budget during the afternoon transition - Part 1: Observed surface TKE budget and boundary layer description for 10 intensive observation period days
}

\author{
Erik Nilsson ${ }^{1,2}$, Fabienne Lohou ${ }^{1}$, Marie Lothon ${ }^{1}$, Eric Pardyjak $^{3}$, Larry Mahrt $^{4}$, and Clara Darbieu ${ }^{1}$ \\ ${ }^{1}$ Laboratoire d'Aerologie, University of Toulouse, CNRS, Toulouse, France \\ ${ }^{2}$ Department of Earth Sciences, Uppsala University, Uppsala, Sweden \\ ${ }^{3}$ Department of Mechanical Engineering, Utah University, Salt Lake City, UT, USA \\ ${ }^{4}$ NorthWest Research Associates, Corvallis, OR, USA \\ Correspondence to: Erik Nilsson (erik.nilsson@met.uu.se, erik.nilsson@aero.obs-mip.fr)
}

Received: 11 September 2015 - Published in Atmos. Chem. Phys. Discuss.: 2 November 2015

Revised: 10 April 2016 - Accepted: 29 April 2016 - Published: 19 July 2016

\begin{abstract}
The decay of turbulence kinetic energy (TKE) and its budget in the afternoon period from midday until zerobuoyancy flux at the surface is studied in a two-part paper by means of measurements from the Boundary Layer Late Afternoon and Sunset Turbulence (BLLAST) field campaign for 10 intensive observation period days. Here, in Part 1, near-surface measurements from a small tower are used to estimate a TKE budget. The overall boundary layer characteristics and mesoscale situation at the site are also described based upon taller tower measurements, radiosoundings and remote sensing instrumentation. Analysis of the TKE budget during the afternoon transition reveals a variety of different surface layer dynamics in terms of TKE and TKE decay. This is largely attributed to variations in the $8 \mathrm{~m}$ wind speed, which is responsible for different amounts of nearsurface shear production on different afternoons and variations within some of the afternoon periods. The partitioning of near-surface production into local dissipation and transport in neutral and unstably stratified conditions was investigated. Although variations exist both between and within afternoons, as a rule of thumb, our results suggest that about $50 \%$ of the near-surface production of TKE is compensated for by local dissipation near the surface, leaving about $50 \%$ available for transport. This result indicates that it is important to also consider TKE transport as a factor influencing the near-surface TKE decay rate, which in many earlier studies has mainly been linked with the production terms of TKE by buoyancy and wind shear. We also conclude that the TKE
\end{abstract}

tendency is smaller than the other budget terms, indicating a quasi-stationary evolution of TKE in the afternoon transition. Even though the TKE tendency was observed to be small, a strong correlation to mean buoyancy production of -0.69 was found for the afternoon period. For comparison with previous results, the TKE budget terms are normalized with friction velocity and measurement height and discussed in the framework of Monin-Obukhov similarity theory. Empirically fitted expressions are presented. Alternatively, we also suggest a non-local parametrization of dissipation using a TKE-length scale model which takes into account the boundary layer depth in addition to distance above the ground. The non-local formulation is shown to give a better description of dissipation compared to a local parametrization.

\section{Introduction}

The atmospheric boundary layer (ABL) over land is inherently marked by a diurnal cycle. The afternoon transition period can be defined as the period from midday maximum heat flux until zero-buoyancy flux (Nadeau et al., 2011). In this paper we use this definition and focus our study on the afternoon transition period. It is well known as a period of turbulence decay in relationship to the diminishing near-surface energy input. This phase of the diurnal cycle is challenging from both an observational and modeling perspective due to 
its transitory nature and that most of the forcings are small in its later part. The afternoon transition starting in a midday well-mixed convective turbulence regime has an important influence for the onset conditions for the usually more pronounced regime change to a heterogeneous and intermittent state with a residual layer overlying a stably stratified surface layer when entering into the evening transition (Stull, 1988). The differences between the very different convective regime and stable regime have a great influence upon, for instance, atmospheric dispersion as shown in, for example, Taylor et al. (2014). We focus here on the afternoon period before stable stratification starts, as we consider that there has been a lack of focus on this in previous studies and that better understanding the onset conditions for the evening transition is of great importance.

Many studies, as discussed in Lothon et al. (2014), have provided insight into the late afternoon or evening transitions without being specifically dedicated to this purpose. The recent study of Wingo and Knupp (2015) also points out that observational study has become a priority. In the absence of a specific field campaign with this focus the Boundary Layer Late Afternoon and Sunset Turbulence (BLLAST) experiment was carried out in June and July 2011 at the "Plateau de Lannemezan" in southern France (Lothon et al., 2014). The site is located on a plateau of about $200 \mathrm{~km}^{2}$ at about $600 \mathrm{~m}$ a.s.l. and is a few kilometers from the Pyrenean foothills and about $45 \mathrm{~km}$ from the highest peaks of the Spanish border.

In general, it may be concluded from the extensive review of existing literature provided in Lothon et al. (2014) that the decay of turbulence depends on the formulation of the decrease in the surface-atmosphere exchanges. For instance, the prescribed surface sensible heat flux or surface temperature affects the decay, but no consensus on an exact relationship between forcings and turbulence kinetic energy (TKE) decay rate has been reached. Several studies have described the governing TKE budget in sheared convective boundary layers and surface layers using measurements (Wyngaard and Coté, 1971; Caughy and Wyngaard, 1979; Högström, 1990; Frentzen and Vogel, 1992) and large-eddy simulation (LES) results for convective boundary layers (e.g., Moeng and Sullivan, 1994; Pino et al., 2003). See also discussions in Fedorovich and Conzemius (2008). In addition, Kumar et al. (2006) and Rizza et al. (2013) conducted LES of the diurnal cycle, whereas van Driel and Jonker (2011) carried out an idealized study and analysis of periodically varying surface heat flux and its impact on boundary layer height and TKE.

Recent simulations (Darbieu et al., 2015) have also been used to study TKE and other turbulence characteristics such as anisotropy, evolution of spectra and integral length scales during the afternoon transition. This was also studied by Pino et al. (2006) using LES by prescribing an instantaneous change to zero-buoyancy flux, similar to Nieuwstadt and Brost (1986) but with the additional effect of shear production. Grant (1997) also provided an observational study for

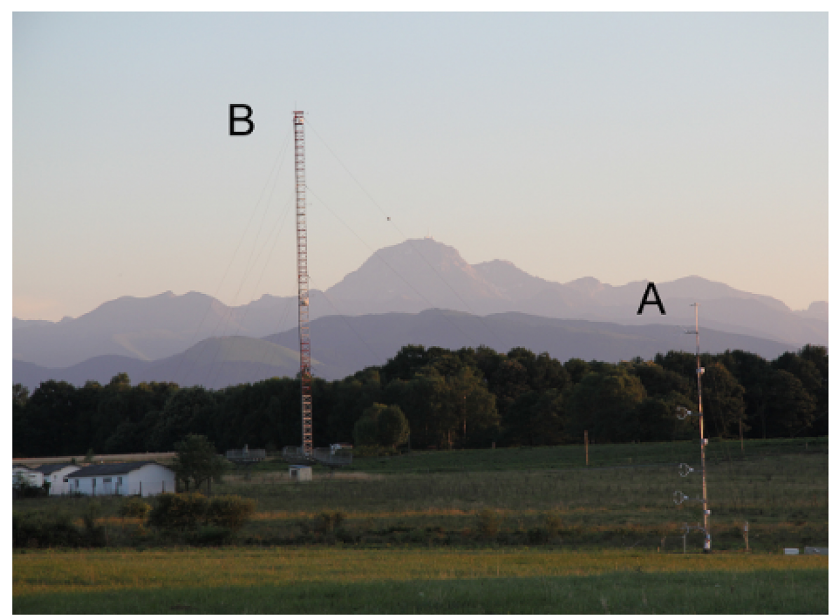

Figure 1. The figure is showing the two main measurement towers and the Pyrenees mountain range in the background. The small divergence site tower is marked with $\mathrm{A}$ and taller $60 \mathrm{~m}$ tower is marked with B.

the evening transition and Goulart et al. $(2003,2010)$ studied the afternoon decay period in still unstable stratification with a theoretical spectral model and LES data. Turbulence kinetic energy and its decay during the afternoon transition have also been specifically studied from measurements by Nadeau et al. (2011), who also managed to model the nearsurface TKE relatively successfully based on a formulation for heat flux and dissipation ignoring other influences. Little attention has, however, been given to transport of TKE in many of the earlier studies, with reasonable arguments that it will not affect the bulk TKE level when integrating over the entire turbulent boundary layer (Nieuwstadt and Brost, 1986; Nadeau et al., 2011). Over a limited vertical extent, however, such an argument needs to be examined further. The study by Dupuis et al. (1997), for instance, suggests that a significant near-surface transport of TKE can occur in homogeneous conditions over the ocean, and Puhales et al. (2013) focused on the height variation in transport terms from LES. Shear production of TKE has also been discussed as a cause that can maintain near-surface TKE even when the buoyancy flux decays at the end of the afternoon, but no study has, to our knowledge, specifically focused on the TKE budget during the afternoon transition from an observational perspective to assess the relative importance of these factors.

In this study, we present a TKE budget from field observations and use it to discuss the governing terms that influence TKE decay rate in the surface layer over a grass surface during the afternoon transition. Our analysis is based on 10 intensive observation period (IOP) days using measurements from the small divergence site tower (see Fig. 1) located at Site 1 from the BLLAST field campaign (Lothon et al., 2014). We then follow up our results with simple modeling of TKE in our companion paper, Nilsson et al. (2016). 
The main data sets and methods used in this study are presented in Sect. 2. For further information on the BLLAST data set, see also the overview paper Lothon et al. (2014). In Sect. 3, some overall boundary layer characteristics are described to guide the reader about the variation in surface layer statistics in relationship to the larger-scale variations in wind and mixed layer depth that occur between the 10 IOP days. In Sect. 4, an hourly near-surface TKE budget is presented for each afternoon period and a classification based upon wind speed and the size and variation in the dominant TKE budget terms is presented. Furthermore, mean TKE tendency or decay rate for the afternoons is presented. Relationships between TKE tendency and observed dissipation rate, shear and buoyancy effects are also presented. The TKE budget is normalized using a local friction velocity and measurement height for comparison to previous studies. Observed near-surface variation in dissipation rate with height is also investigated further. Finally, a non-local parametrization of dissipation is proposed and evaluated. This is followed by summary and conclusions in Sect. 5.

\section{Data and methods}

\subsection{Data screening and treatment}

Here we describe the main data sets used in this study and provide details about screening and treatment of the data. Turbulence data $(20 \mathrm{~Hz})$ of wind components $(u, v$ and $w)$ and sonic temperature $T_{\mathrm{s}}$ measured with Campbell Scientific anemometer-thermometers (CSAT) at the divergence site tower as well as ultrahigh-frequency (UHF) wind profiler data are downloadable from http://bllast.sedoo.fr/database/ (BLLAST, 2015).

\subsubsection{Smoothing and gap filling of UHF wind fields}

The data set of UHF wind profiler data is available at an average temporal resolution of $5 \mathrm{~min}$ and vertical spatial resolution of $75 \mathrm{~m}$ starting at a height of $175 \mathrm{~m}$. We use the UHF profiler data and radiosoundings from Site 1 (closest to the two towers). There was also a second UHF profiler operating during the field campaign $(5.1 \mathrm{~km}$ away) which gave similar results (Said et al., 2012). The data loss was less than $2 \%$ below $1900 \mathrm{~m}$ (on average about $0.7 \%$ ). Increasingly smaller data coverage is found for the layers above; at $2350 \mathrm{~m}$ it had about $10 \%$ missing values and at $3000 \mathrm{~m}$ around $33 \%$. There was also some more frequent data loss at the lowest level (2.4\%) compared to the second lowest $(0.74 \%)$.

We used software from Garcia (2010) to perform gap filling and smoothing of the wind vector field. The data were first placed on a uniform time-height grid according to minute of observation and using the $75 \mathrm{~m}$ vertical resolution. Then a smoothing parameter $S$ of $10^{-1}$ was used with five repeated iterations, and an extra smoothing in time using a 5 min running mean value was used for time series from each vertical level. The performance was deemed as satisfactory for the most part, except for a period in the early morning and before sunrise on 26 June, when the method caused the smoothed wind speed to be clearly underestimated. Also, during some other periods in the morning or during stable nighttime conditions the performance is not as good as in unstable conditions, but this will have little or no effect for the afternoon periods, which are our main focus.

At times, it can be argued that the gap-filled wind direction fields miss too much of the real variability that was indicated by the available non-gap-filled and unsmoothed data (and sometimes at the $60 \mathrm{~m}$ tower). This was more frequent on days with low wind speed, but the smoothed and gap-filled fields were nevertheless used to describe the overall boundary layer behavior in wind in Sect. 3 (and Appendix A). The time-height smoothed fields were also needed for reasonable tracking of persistent wind speed gradients near the inversion, which was otherwise at times obscured by more random fluctuations in the wind field (less persistent in both time and vertical direction).

\subsubsection{Screening and treatment of turbulent time series from tower measurements}

After manually checking time series of wind and temperature, the four upper measurement levels at the small divergence site tower $(2.23,3.23,5.27$ and $8.22 \mathrm{~m}$ ) were chosen for the main analysis and TKE budget calculations. Out-ofrange values above 100 or below -100 of any wind component or temperature were first removed from all time series. Outliers outside \pm 4 standard deviations from the mean value for each hour were also removed before further calculations. Each hourly time series was also manually checked and suspicious "noisy" periods were error-flagged. If any $10 \mathrm{~min}$ period during an hour had less than $90 \%$ of data coverage, that hour was excluded from TKE budget calculations. Linear interpolation was applied when needed. Most of the time the data loss was small (less than $2 \%$ ). This procedure may seem restrictive, but most excluded data belonged to non-IOP days and/or stable conditions, which are not the focus here.

Fluxes were calculated in a rotated coordinate system (Kaimal and Finnigan, 1994, natural wind coordinates with double rotation). We will use an overbar to denote a $10 \mathrm{~min}$ averaging operator. For TKE budget terms, a subsequent averaging over $1 \mathrm{~h}$ is, however, used to reduce scatter and study the more slow trends of the different terms. Our choice of a $10 \mathrm{~min}$ averaging period helps remove the sometimes observed large low-frequency variability, which we speculate could be partly connected to the larger topographical differences that exist outside of the "Plateau de Lannemezan" area more than 2-4 km from the site. Near the surface, fluctuations in TKE and variance values from one $10 \mathrm{~min}$ period to the next was not as large as found on the $60 \mathrm{~m}$ tower. At the $60 \mathrm{~m}$ tower the quality of spectra in the high-frequency range 
also appeared more noisy and questionable, and budget calculations were not performed.

\subsection{Determination of the terms in the TKE budget}

The governing equation for TKE in a sheared convective boundary layer under the assumption of horizontally homogeneous turbulence and no advection is given by Stull (1988):

$$
\begin{aligned}
& \underbrace{\frac{\partial E}{\partial t}}_{\text {TKE tendency }}=\underbrace{-\overline{u^{\prime} w^{\prime}} \frac{\partial U}{\partial z}}_{\text {Shear production }}+\underbrace{\frac{g}{\bar{\theta} \overline{w^{\prime} \theta_{v}^{\prime}}}-}_{\text {Buoyancy production }} \\
& \underbrace{-\frac{\partial \overline{w^{\prime} E^{\prime}}}{\partial z}}_{\text {Turbulent transport Pressure transport }} \underbrace{-\frac{\partial \overline{w^{\prime} p^{\prime} / \rho_{0}}}{\partial z}}_{\text {Dissipation }} .
\end{aligned}
$$

Here TKE $(=E)$ denotes $1 / 2\left(\overline{u^{\prime 2}}+\overline{v^{\prime 2}}+\overline{w^{\prime 2}}\right)$, where $u^{\prime}$, $v^{\prime}$ and $w^{\prime}$ are instantaneous deviations of, respectively, the along-wind, cross-wind and vertical wind components from their respective mean values. $U$ is the magnitude of the mean wind, which varies with height $z ; g$ is acceleration of gravity; $\bar{\theta}$ is mean absolute temperature; $\theta_{\mathrm{v}}^{\prime}$ is the instantaneous deviation of virtual temperature from its mean value; $\rho_{0}$ is air density; $p^{\prime}$ is the instantaneous deviation of air pressure; and $\epsilon$ is the mean dissipation rate of TKE.

We have given the buoyancy term the subscript buoyancy production of TKE since we limit our study to the afternoon period before stable stratification starts. Hence, it is always a positive term in our case. The physical interpretation of the six terms in Eq. (1), from left to right, is hence the local time rate of change of TKE, shear production of TKE, buoyancy production of TKE, vertical divergence of the turbulent transport of TKE, vertical divergence of the pressure transport of TKE, and dissipation rate of TKE.

\subsubsection{Tendency of TKE}

Firstly, we determined TKE $(=E)$ values for every $10 \mathrm{~min}$ sample followed by forming a $1 \mathrm{~h}$ running mean TKE time series. This was done to avoid studying very temporary fluctuations in TKE which showed little correlation to, for instance, the generally decaying sensible heat flux during the afternoon transition. A second-order finite-difference approximation was then applied to the running mean time series to obtain estimates of TKE tendency at 12:30, 13:30 UTC, etc. for the afternoon.

The variations in TKE on shorter timescales may potentially be related to advection of TKE, temporary shading from clouds causing changes in the near-surface energy balance, fast variations in near-surface wind gradients and fluxes, or other effects causing non-stationarity in TKE (and especially in horizontal wind variances). Statistical sampling error is also a large source of variability both for variances and turbulent fluxes (Billesbach, 2011). Here we will, however, focus on the more persistent slow trends and changes observed in TKE in relationship to persistent changes in the other budget terms.

\subsubsection{Shear production of TKE}

This term is evaluated from the shearing stress $\overline{u^{\prime} w^{\prime}}$ and the mean wind gradient at each height $(2.23,3.23,5.27,8.22 \mathrm{~m})$ with turbulence measurements. Shearing stress was calculated from measured time series of vertical and along wind velocity components. A polynomial expression was fit between wind speed and logarithmic height to estimate the wind gradient at all four heights. The calculation procedure was compared to using a second-order finite-difference approximation to estimate the wind gradient for the 3.2 and $5.3 \mathrm{~m}$ level. The results indicated only small differences.

\subsubsection{The buoyancy production term}

This term requires only the measurement of the turbulent flux of virtual temperature, which is nearly equal to the corresponding flux of the directly measured "sonic" temperature at each turbulence level, and measurements of the mean temperature. The $8.2 \mathrm{~m}$ temperature was chosen as reference temperature $\bar{\theta}$.

\subsubsection{Dissipation}

Dissipation $(D=-\epsilon)$ or dissipation rate, $\epsilon$, was estimated from spectra. Power spectral densities for the $w$ component premultiplied by frequency $n S_{w}(n)$ were plotted on a log-log scale against frequency $n$. According to Kolmogoroff (1941), and further assuming Taylors hypothesis to be valid, the spectral curves in the inertial subrange are predicted to be straight lines with $-2 / 3$ slope in this representation,

$n S_{w}(n)=\frac{4}{3} \alpha_{1} \epsilon^{2 / 3}\left(\frac{2 \pi n}{U}\right)^{-2 / 3}$,

so that

$\epsilon=\frac{2 \pi n}{U}\left[\frac{3 n S_{w}(n)}{4 \alpha_{1}}\right]^{3 / 2}$.

Here $\alpha_{1}$ is the universal Kolmogorov constant $\approx 0.52$ (Wyngaard and Coté, 1971; Högström, 1996) and $n$ must be in the range with $-2 / 3$ slope. In practice, each hour of data analyzed was split into eight periods of $7.5 \mathrm{~min}$ and dissipation rate was estimated by fitting a line to a range of wave numbers above 0.1 and then using the obtained relationship to calculate dissipation rate using the equation shown above. The mean value and standard deviation of the eight estimates was calculated and the mean value is used as an average dissipation rate estimate for the hour. We chose to use the vertical wind spectra for our calculation of dissipation since it appeared less influenced by non-stationarity than the horizontal wind components. 

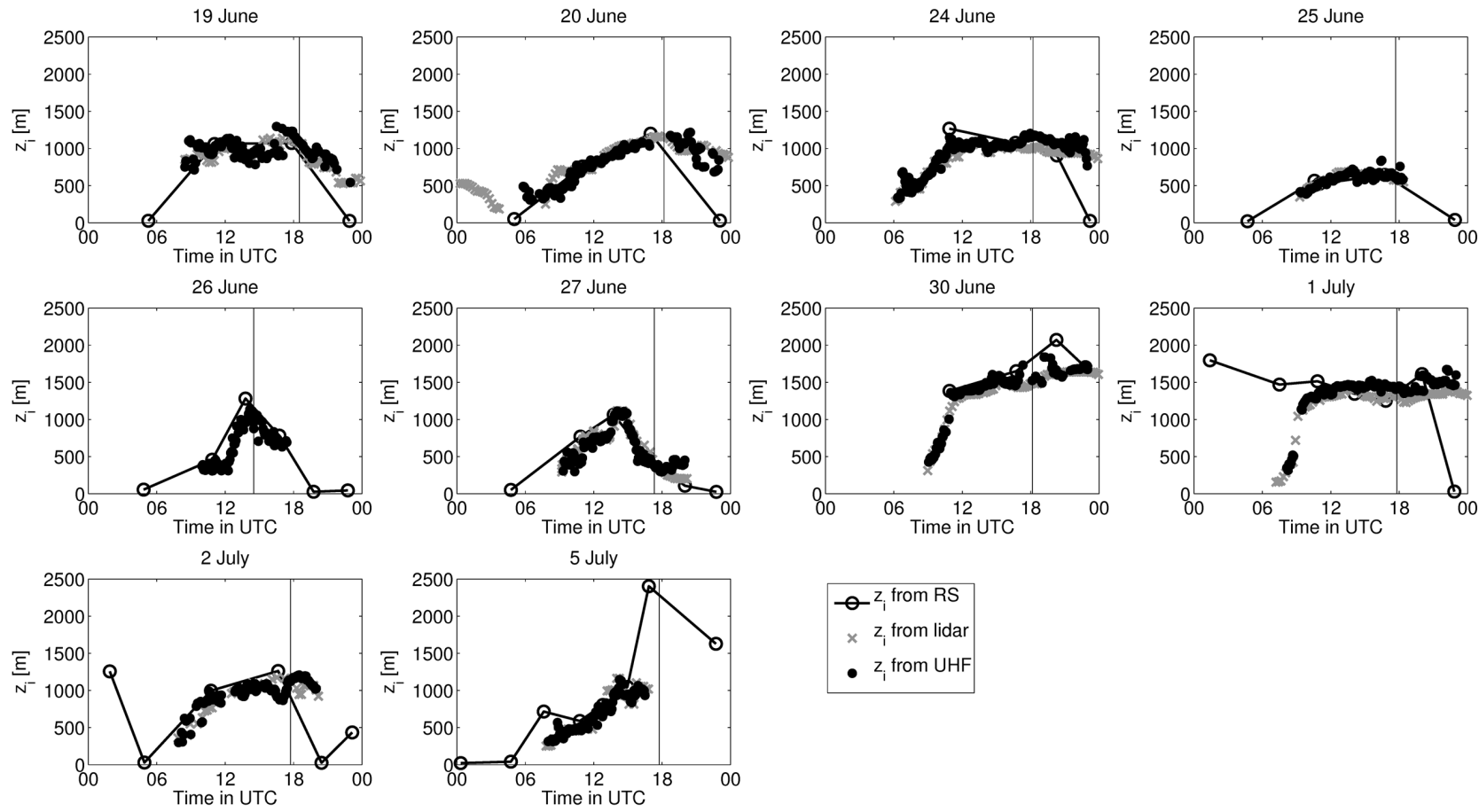

Figure 2. Boundary layer depth $\left(z_{i}\right)$ estimates from (black dots) UHF wind profilers (based on reflectivity), (grey crosses) aerosol lidar (based on backscatter) and (open circles) radiosoundings (based on the strongest potential temperature gradient). A vertical line has been included to mark the timing of zero-buoyancy flux at surface.

\subsubsection{Transport}

Transport is given by two parts: pressure transport and turbulent transport. Pressure transport, $T_{\mathrm{p}}=-\frac{\partial \overline{w^{\prime} p^{\prime} / \rho_{0}}}{\partial z}$, is well known to be very difficult to measure directly. We attempted to calculate the pressure velocity covariance from a microbarometer and vertically displaced sonic anemometer at the so-called "small-scale heterogeneity site" (which is located about $100 \mathrm{~m}$ away from the $60 \mathrm{~m}$ tower and $400 \mathrm{~m}$ away from the divergence site tower). There was, however, no clear leveling off in Ogive curves and the results were very scattered for this parameter. Hence, due to the uncertainty in this parameter, estimates of this term are not reported.

The turbulent transport, $\quad T_{\mathrm{t}}=-\frac{\partial \overline{w^{\prime} E^{\prime}}}{\partial z}=$ $-\frac{1}{2} \frac{\partial}{\partial z}\left(\overline{w^{\prime} u^{\prime 2}}+\overline{w^{\prime} v^{\prime 2}}+\overline{w^{\prime} w^{\prime 2}}\right)$, was also calculated directly for each turbulence level at the divergence site. Although the sum of the third-order moments often showed a diurnal cycle, the uncertainty introduced by taking a vertical gradient led to large scatter in estimates of the turbulent transport term. In fact, the profile of estimated $\overline{w^{\prime} E^{\prime}}$ was found to be mostly non-monotonic regardless of choice of averaging time and pre-filtering procedure.

Therefore, we believe that a better estimate of the total transport (being equal to the sum of turbulent and pressure transport) is obtained from the residual of the TKE budget. Hence, we determine the total hourly transport value $T$ by the following calculation:

$T=\frac{\partial E}{\partial t}-S-B-D$,

where the other budget terms have been averaged for each hour centered around 12:30, 13:30 UTC, etc. for the afternoon period. It should be noted that $T$ thereby absorb errors in the terms on the right-hand side and possibly influence from horizontal transport.

\section{Summary of overall boundary layer situation and its use for interpretation of surface layer TKE budget}

Here, we summarize some of the atmospheric conditions for 10 IOP days. The description is based on boundary layer depths from radiosoundings (using a maximum potential temperature gradient criteria), UHF wind profiler (determined from reflectivity based on the refractive index of air, which is related to pressure, temperature and specific humidity; see Cohn and Angevine, 2000) and lidar (see Fig. 2). Wind speed and direction from tower measurements and the lowest UHF profiler level are presented in Figs. 3 and 4. In Appendix A, a day-by-day description divided up into the four main observational periods - 19-20, 24-27, 30 June2 July, and 5 July - is also provided based on temperature and humidity (from the $60 \mathrm{~m}$ tower and radiosoundings) and a more detailed view of height-time variation in wind from 

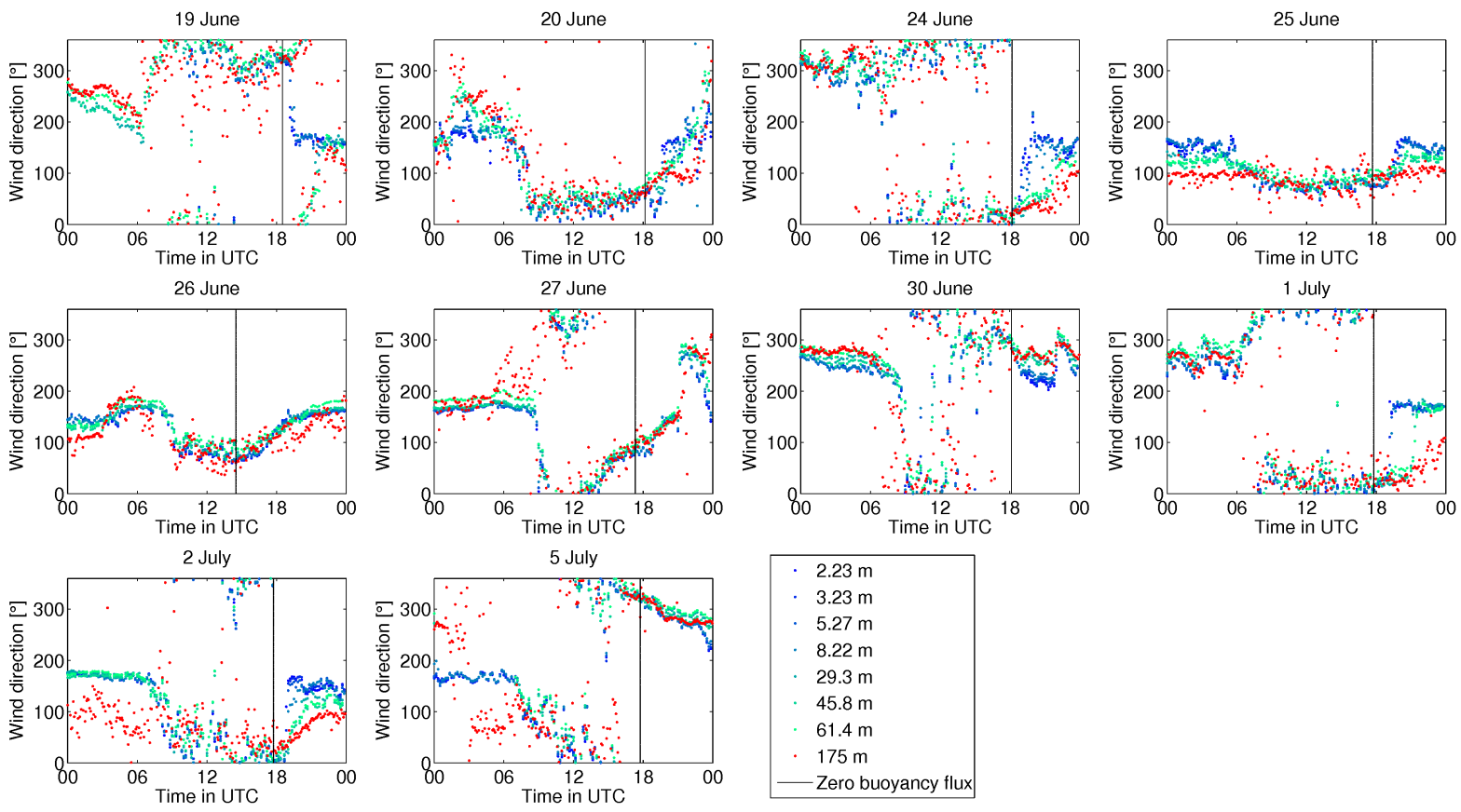

Figure 3. Time series of wind direction for each IOP day, color-coded according to measurement height such that the small-tower measurements $(2-8 \mathrm{~m})$ are shown in bluish colors, high tower measurements $(30-60 \mathrm{~m})$ in greenish colors and the lowest UHF profiler level (175 $\mathrm{m})$ in red. A vertical line is inserted to show the timing of zero-buoyancy flux for each day.

UHF (see Figs. A1 and A2). The site longitude is around $0.21^{\circ} \mathrm{E}$; consequently UTC, which is very similar to local solar time, is used as the time reference hereafter.

For even further information about the synoptic situation and standard radiosounding, we also refer the reader to the day-by-day description of IOP days in Blay-Carreras (2013) and the day-by-day analysis of synoptic and meteorological conditions (Nilsson, 2014) with more figures that were used to characterize the situation for these 10 IOP days. These reports are found on the BLLAST webpage (BLLAST, 2015), which also has a collection of other BLLAST-related studies.

For these 10 IOP days many different conditions in terms of boundary layer depth, wind speed and moisture conditions occurred. This was found even though there were mainly fairweather days with generally no, or a small amount of, cloud cover, except on 24 and 30 June, which had more clouds (Lothon et al., 2014). The boundary layer depth (here shown in Fig. 2), estimated from lidar measurements, was broadly categorized based on its evolution in Lothon et al. (2014), with 19 June and 1 July having a rapid growth and leveling inversion in the afternoon. For 20, 24, 25 and 30 June and 2 July, a more typical growth and leveling inversion was instead found (Lothon et al., 2014), and for 26 and 27 June and 5 July the situations were categorized with slower growth and a rapidly decreasing inversion top in the late afternoon. On 5 July, for the late afternoon, the top inversion was more diffuse than on some of the other days. Identifying the inver- sion based on potential temperature gradient sometimes gave a different result with higher boundary layer depth estimate.

From the UHF wind profiler data provided in Appendix $\mathrm{A}$ it is clear that the overall boundary layer flow situation involves an upper wind speed gradient which is often present, for at least 6 out of 10 days, possibly excluding 25-30 June, when it was weaker and/or more diffuse. The height of the strong wind speed gradient marks a dynamical separation of the boundary layer flow with northerly or easterly wind (in daytime) from the dominant westerly flow above. The northeasterly boundary layer wind is most of the time linked with a mountain-breeze circulation on the site. The mainly westerly or weak flow above the boundary is related to the synoptic weather situation on the different days. When the boundary layer flow, related to the complex mesoscale situation at the site, encounters and mixes with the flow above, a layer of reduced wind speed in the upper parts of the boundary layer also occurs, as can be observed for several days (see Fig. A1 and, for instance, 20, 25 and 26 June and 1, 2, and 5 July).

On some of the warm days (25-27 June) the wind direction in the boundary layer is more easterly in daytime. This is related to a low-pressure area in the lower troposphere over the Gulf of Lion in the Mediterranean (Lothon et al., 2014). Wind speed is (as seen from Figs. 4 and A1) variable in both time and space, but the lowest UHF level is quite representative of the boundary layer flow up to some height where the wind turns and mixing of easterly boundary layer flow and westerly synoptic or mesoscale flow occurs. Wind speed be- 

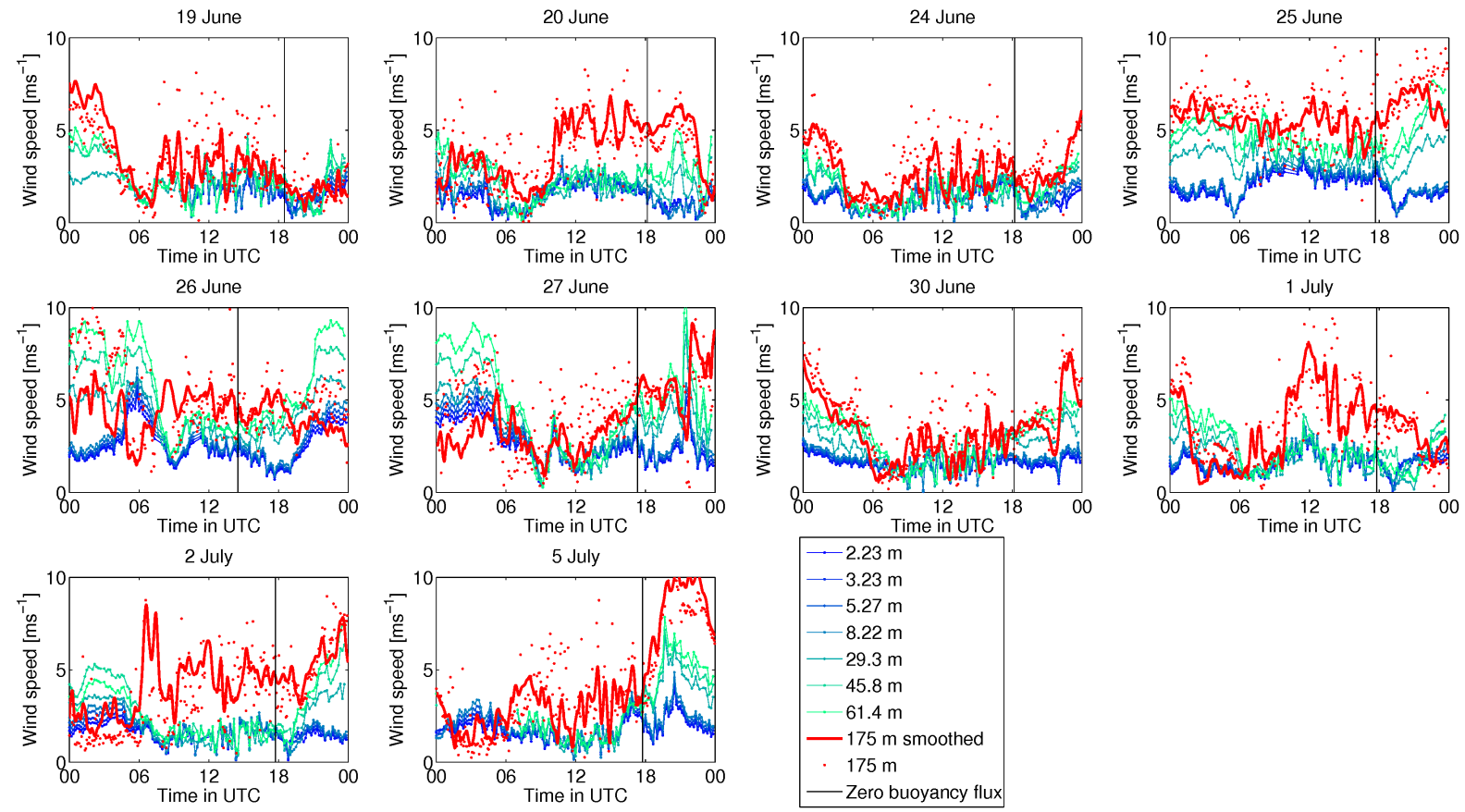

Figure 4. Time series of wind speed with the same color-coding as used in Fig. 3. Here also a 10 min height-time smoothed red line is shown for the UHF profiler data at $175 \mathrm{~m}$.

low $100 \mathrm{~m}$ is less than $5 \mathrm{~m} \mathrm{~s}^{-1}$ most of the days, except on 26 and 27 June and at the end of 5 July.

Smaller differences in wind characteristics are generally observed on the $60 \mathrm{~m}$ tower and the small tower between the days than in the boundary layer in general. Wind direction is reasonably consistent on both towers and the lowest UHF level during daytime, but once the buoyancy flux becomes negative (marked by a vertical black line in Fig. 3), the wind direction on the small tower often shifts rapidly towards south (19, 20, 24, 25 and 30 June and 1 and 2 July). This change is related to a shallow drainage flow which was further studied by Nauta (2013) for some days and for 2 July also by Román-Cascón et al. (2015). This wind turning in the shallow layers near the surface related to very local terraininduced effects precedes the setup of a common larger-scale mountain-breeze circulation (Román-Cascón et al., 2015) which is often recognized in time series about $2-3 \mathrm{~h}$ later. The mountain-breeze circulation for this site has been studied by mesoscale modeling (Jiménez and Cuxart, 2014, 2015).

When the atmosphere is stably stratified, it is important to remember that the surface TKE budget gives very limited information about upper layers. For unstably stratified conditions there is, however, no reason to believe that such decoupling issues exist, and as we shall see in Sect. 4.3, mixedlayer dynamics (linked with boundary layer depth) have an influence on dissipation rate even very near the surface. Surface layer wind is used in the TKE budget analysis in the following sections. Many of the variations in observed surface layer wind on the small tower are, however, clearly linked and caused by variations in boundary layer wind observed on the $60 \mathrm{~m}$ tower and by the UHF profiler. Therefore, this instrumentation provides important additional information for interpretation of surface layer results.

When comparing sensible heat fluxes shown in Lothon et al. (2014) to the overall boundary layer description presented here, it is also clear that warmer days (e.g., 26 and 27 June) in general have lower fluxes and colder days higher fluxes (e.g., 19, 24 June and 1 July). This is linked to the ground-air temperature difference on the different days. This is an important factor in determining the size of the buoyancy production term in the TKE budget during the afternoon transition. The moisture content is also important, although this may become even more important in the evening and night (not studied in detail here), as indicated by the higher observed specific humidity reported in Table A1.

\section{TKE budget and near-surface analysis}

\subsection{Overview of observed TKE budget for 10 IOP days}

In Fig. 5, we present the observed hourly TKE budget for each afternoon transition period from 12:00 UTC (normalized time 0 ) to zero-buoyancy flux (normalized time 1) for all four levels of the small divergence site tower. The measurement levels $(2.23,3.23,5.27$ and $8.22 \mathrm{~m})$ are shown as dashed, dash-dotted, full and dotted lines, respectively. 

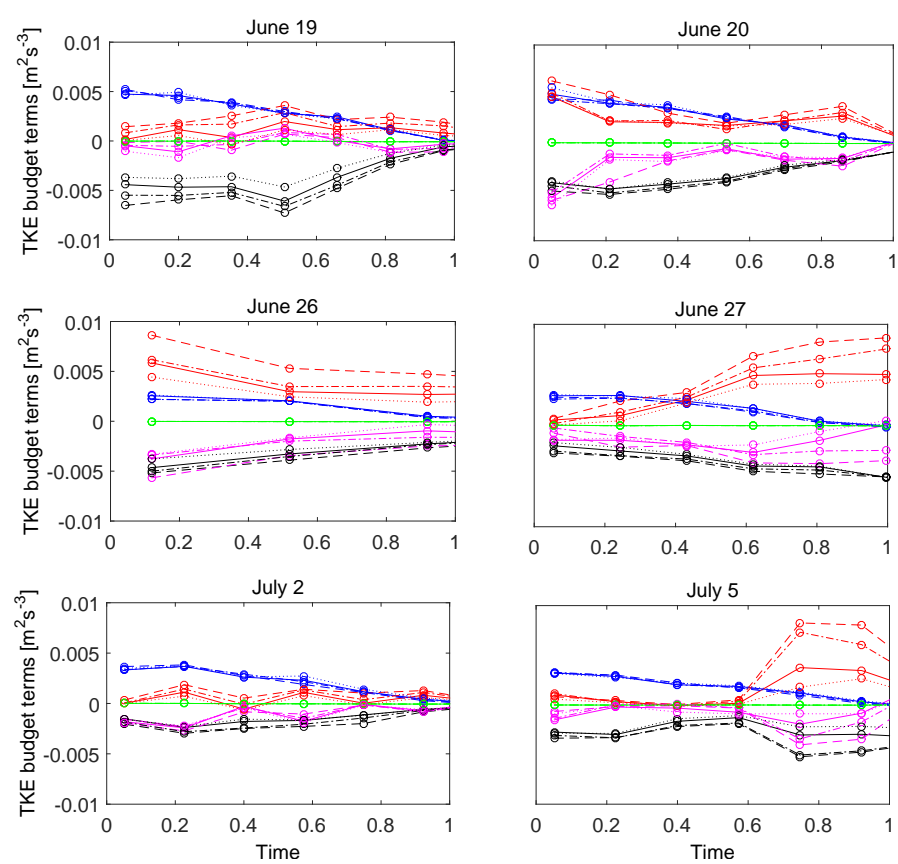
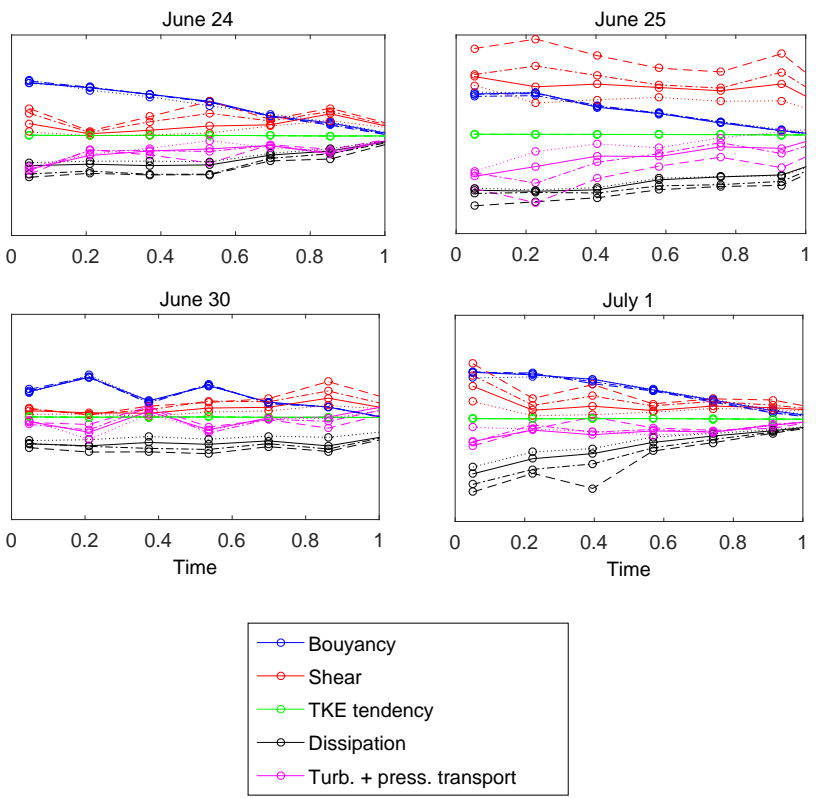

Figure 5. Turbulence kinetic energy budget terms are shown on the $y$ axis as a function of normalized time for the afternoon period between 12:00 UTC (denoted 0) and the time of zero-buoyancy flux (denoted 1). Here, dashed lines show the $2.23 \mathrm{~m}$ results, dash-dotted $3.23 \mathrm{~m}$, full lines $5.23 \mathrm{~m}$ and dotted lines $8.23 \mathrm{~m}$. The colors denote the different budget terms: buoyancy production (blue), shear production (red), dissipation (black), TKE tendency (green) and transport (magenta).

For buoyancy production (in blue), only very small height variations are observed near the surface and a general decrease with time during the afternoon is observed for all days. On 30 June, this general picture is partly interrupted by the presence of clouds changing the energy balance.

Also, the dissipation rate (in black) is observed to have a general decrease during the afternoon transition for 8 out of 10 IOP days. Most significant deviations are found on days with an increase in shear production during the afternoon, leading to a clear increase in dissipation. Hence, shear production plays an important role near the surface in the TKE budget for most of these 10 IOP days. It has the most pronounced height dependence out of all budget terms, with higher values near the surface. The strongest dissipation rate is also found closest to the surface, but the height variation in dissipation is smaller.

Given that the TKE tendency (in green) is much smaller (2 orders of magnitude) than the other budget terms this implies that the sum of turbulent and pressure transport (in magenta) compensates for remaining height variation in the budget. Because the tendency term of TKE is much smaller than the other budget terms, we will refer to the hourly TKE as evolving in a quasi-stationary way. Here, we use the term quasistationarity to mean that the tendency of TKE is small in comparison to the other budget terms. This result of quasistationarity is consistent with the observed slowly evolving mean TKE levels in LES for a large part of the afternoon of 20 June as described in Darbieu et al. (2015). Although the
TKE tendency then increased somewhat in the late afternoon in the LES, a threshold of about $-1.1 \times 10^{-5} \mathrm{~m}^{2} \mathrm{~s}^{-3}$ was used in Darbieu et al. (2015) to indicate the faster decay, and this is still quite a small TKE tendency.

The height variation in transport is found to mainly be linked with local shear production. The transport term is consistently a negative term in the TKE budget. This implies transport of near-surface-produced turbulence to the surrounding environment and upper parts of the boundary layer. Only a few occasions with positive transport term were observed in connection to changing cloud cover and more variable dissipation estimates.

To investigate general differences between the different days, we calculated statistics for each budget term during the afternoon period. These statistics are provided in Appendix B and some of the most important findings are discussed in Appendix B and only briefly restated here.

Variations in shear production between afternoons in Tables B1 and B2 were found to be significantly larger than buoyancy production. Variations in dissipation and transport between different afternoons were thereby found to be mostly related to varying shear production this close to the surface. Larger variations were observed in both the transport and dissipation term compared to the buoyancy term, meaning that buoyancy alone cannot explain differences in mean values between different afternoons for these terms. The three lowest TKE mean values in Table B3 occurring on 30 June and 2 and 5 July had the lowest wind speed and 


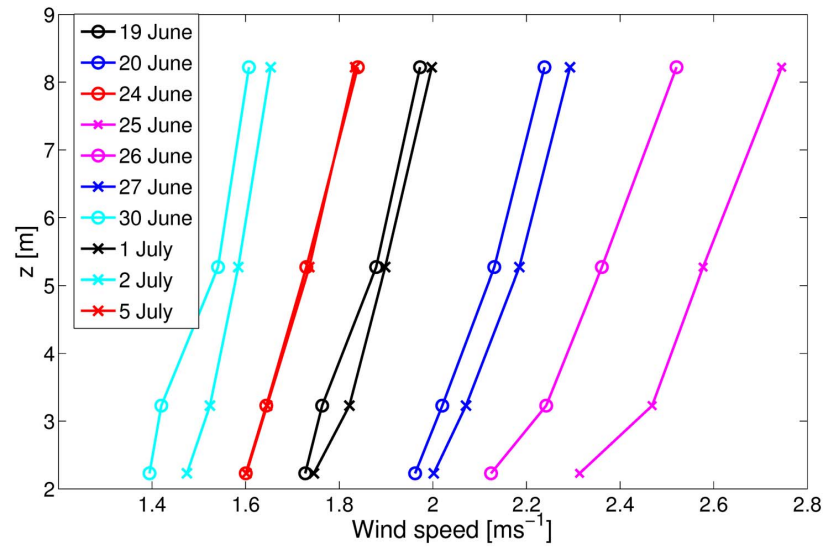

Figure 6. Vertical profile of mean near-surface wind speed for all 10 IOP afternoons with measurements at the small divergence site tower.

25 June, which had the highest wind speed, also had the highest mean afternoon TKE value.

There are, of course, exceptions to the rule that a higher wind speed leads to a higher TKE level; this topic needs to be further discussed. In Fig. 6, we show the mean wind profiles for the 10 afternoons and have placed the same color on the two most similar profiles to facilitate further discussions to come. It is directly clear that 24 June and 5 July (in red) have essentially equal mean wind for the afternoon as a whole, yet from Table B3 we note that average TKE values are higher for 24 June. This is likely related to a higher mean buoyancy production of about $3.4 \times 10^{-3} \mathrm{~m}^{2} \mathrm{~s}^{-3}$ (the highest in the data set) in comparison to about $1.9 \times 10^{-3} \mathrm{~m}^{2} \mathrm{~s}^{-3}$ for 5 July, which is the lowest in the data set. Hence, several terms need to be considered to understand the observed variations in TKE.

Nevertheless, it is interesting to note that a relatively high negative correlation $(-0.69)$ between the mean afternoon TKE tendency and mean afternoon buoyancy production exists, as shown in Fig. 7a. This is interpreted to imply that, in the case of a strong buoyancy production (both before and during the afternoon), TKE levels at midday are higher and therefore TKE decay rate during the afternoon can become higher. However, it is always small in comparison to other budget terms. A weaker positive correlation (0.33) is found between TKE tendency and shear production, implying that turbulence will decay more slowly during a more shear-driven afternoon as seen in Fig. 7b. This is in general agreement with reduced TKE decay rates for the afternoon found in LES when including wind shear (Pino et al., 2006), and it is also discussed using a theoretical spectral model and LES data by Goulart et al. (2003, 2010). Best linear fit expressions have been included in both panel a and b. Attempts were made to non-dimensionalize the surface layer TKE tendency itself with measurement height and friction velocity and correlate it with various non-dimensional pa- rameters such as $z / L, z_{i} / L$, but it gave decreased correlation in comparison to relating tendency directly to buoyancy production as in Fig. 7a.

\subsection{Classification}

We do a broad summarizing classification of the 10 different afternoons in Table 1 based on the TKE budget mean values of Tables B1 and B2. In Part 2, when attempting to model TKE and TKE decay, we discuss more details and variations.

For this broad classification we take as a starting point the terms of largest variation at the $2 \mathrm{~m}$ level as a reference level for this classification. The days were placed into three categories (higher, moderate and weaker) in terms of mean wind speed, with 20, 25, 26 and 27 June having the higher mean wind speeds and 30 June and 2 July the weakest winds of the data set. An " $X$ " marker denotes placement in a category. When the variation within the afternoons justifies only one part of the afternoon belonging to a given category, we denote this with parentheses, e.g., "(p)". For the moderate category, we also indicate with "l" or " $h$ " whether the variable mainly departs toward the lower or higher category. In a similar way shear production, transport and dissipation are classified into three categories (higher, moderate and weaker). For buoyancy production, the variations were smaller and only two categories (higher and moderate) are used. For dissipation, we also mark the special cases of 27 June and 5 July with increasing dissipation during the afternoon with "inc" within parentheses.

If the mean value of shear production at the $2 \mathrm{~m}$ level is above $3.5 \times 10^{-3} \mathrm{~m}^{2} \mathrm{~s}^{-3}$, it is considered higher (marked with bold font), and if it is lower than $2.0 \times 10^{-3} \mathrm{~m}^{2} \mathrm{~s}^{-3}$, it is considered weaker (underlined). The moderate category is marked in italics. These arbitrary limits illustrate an expected correspondence between the mean afternoon wind speed and classification based on mean shear production for these afternoons, but it is clearly a relative classification since mean afternoon wind speed was always below $3 \mathrm{~m} \mathrm{~s}^{-1}$.

For transport, a mean value below $-2.5 \times 10^{-3} \mathrm{~m}^{2} \mathrm{~s}^{-3}$ at the $2 \mathrm{~m}$ level was considered stronger transport out of the near-surface layers and a mean value above $-1.5 \times$ $10^{-3} \mathrm{~m}^{2} \mathrm{~s}^{-3}$ is marked as weaker. Bold font and italics are added on the days with higher shear production to illustrate that on these afternoons the transport is also higher or moderate. Underlining is instead added for days with weaker or moderate shear production with partly lower shear production during the afternoon, and it can be seen that these have weaker or moderate transport values.

For dissipation, a mean value equal to or lower than $-4.5 \times 10^{-3} \mathrm{~m}^{2} \mathrm{~s}^{-3}$ at the $2 \mathrm{~m}$ level is classified as having higher dissipation, and above $-3.5 \times 10^{-3} \mathrm{~m}^{2} \mathrm{~s}^{-3}$ it is considered to have lower dissipation. Bold font and underlining are added for days with higher shear production and these are found to have higher or moderate dissipation, whereas the two days with weakest shear production had the weakest 

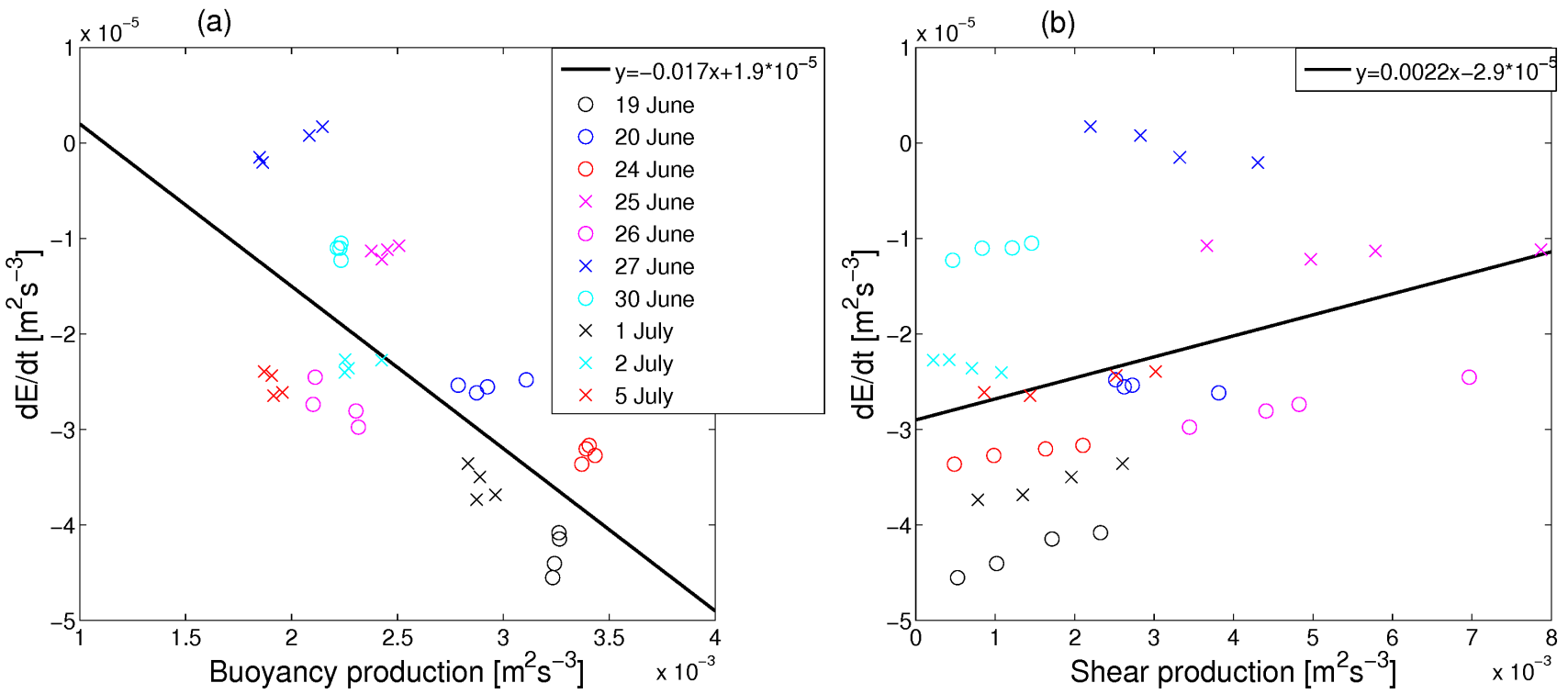

Figure 7. Average TKE tendency for each afternoon is shown as a function of buoyancy production in panel (a) and shear production in panel (b).

Table 1. TKE budget classification of the 10 IOP afternoons. Here, wind speed, shear production, transport and dissipation have been classified into three categories ("h": higher; "m": moderate; "w": weaker) and the buoyancy production into two categories ("h" and "m") based on the mean values for the afternoon (see text for exact limits). Furthermore, in parentheses "p" denotes whether only part of the afternoon is considered to belong to the category. For the moderate category an extra "l" or " $h$ " indicates whether the variable is mainly departing towards the lower or higher category. For dissipation, two days are denoted with "(inc)" to indicate that dissipation increased during the afternoon. To interpret some of the main effects of higher or weaker wind speed on the TKE budget, combinations of underlining, italics and bold font have been added to the table (see text for further explanation).

\begin{tabular}{|c|c|c|c|c|c|c|c|c|c|c|c|c|c|c|}
\hline \multirow[b]{2}{*}{ Category } & \multicolumn{3}{|c|}{$\begin{array}{l}\text { Wind } \\
\text { speed }\end{array}$} & \multicolumn{3}{|c|}{$\begin{array}{c}\text { Shear } \\
\text { production }\end{array}$} & \multicolumn{2}{|c|}{$\frac{\text { Buoyancy }}{\text { production }}$} & \multicolumn{3}{|c|}{ Transport } & \multicolumn{3}{|c|}{ Dissipation } \\
\hline & $\mathrm{h}$ & $\mathrm{m}$ & w & $\mathrm{h}$ & $\mathrm{m}$ & $\mathrm{w}$ & $\mathrm{h}$ & $\mathrm{m}$ & $\mathrm{h}$ & $\mathrm{m}$ & w & $\mathrm{h}$ & $\mathrm{m}$ & w \\
\hline 19 June & & $X$ & & & $X(p l)$ & & $X$ & & & & $\underline{X}$ & $X$ & & \\
\hline 20 June & $\mathbf{X}(\mathbf{p})$ & & & $\mathbf{X}(\mathbf{p})$ & & & $X(p)$ & & $X(p)$ & & & & $\underline{X}$ & \\
\hline 24 June & & $X(p l)$ & & & $X(p l)$ & & $\mathrm{X}$ & & & $\mathrm{X}(\mathrm{pl})$ & & & $X \overline{(p l})$ & \\
\hline 25 June & $\mathbf{X}$ & & & $\mathbf{X}$ & & & & $X(p)$ & $X$ & & & $\underline{\mathbf{X}}$ & & \\
\hline 26 June & $\mathbf{X}(\mathbf{p})$ & & & $\mathbf{X}$ & & & & $\mathrm{X}$ & $X(p)$ & & & $\overline{X(p)}$ & & \\
\hline 27 June & $\mathbf{X}(\mathbf{p})$ & & & $\mathbf{X}(\mathbf{p})$ & & & & $X$ & & $X$ & & & $X($ inc $)$ & \\
\hline 30 June & & & $\underline{X}$ & & & $\underline{X}$ & & $X(p)$ & & & $\underline{X}$ & & & $\underline{X}$ \\
\hline 1 July & & $X(p l)$ & & & $X(p l)$ & & $\mathrm{X}(\mathrm{p})$ & & & & $\underline{\bar{X}}$ & & $\mathrm{X}(\mathrm{ph})$ & \\
\hline 2 July & & & $\underline{X}$ & & & $\underline{X}$ & & $X(p)$ & & & $X \overline{(p)}$ & & & $\underline{X}$ \\
\hline 5 July & & $X(p h)$ & & & $X(p h)$ & & & $X$ & & $\mathrm{X}(\mathrm{pl})$ & & & & $X(\overline{i n c})$ \\
\hline
\end{tabular}

dissipation (underlined and in italics). However, also 5 July, which had variable wind during the afternoon, had weaker dissipation and 19 June had higher dissipation, despite its moderate to partly lower shear production. For 19 June, it is hence not possible to draw the conclusion that higher dissipation rate is caused by high shear production; rather, it may be the higher buoyancy production that is the cause.

Finally, for buoyancy production, we have classified higher buoyancy production to imply a mean value for the afternoon of above $2.5 \times 10^{-3} \mathrm{~m}^{2} \mathrm{~s}^{-3}$ and moderate to mean below this limit.

\subsection{Normalization of the TKE budget terms}

To compare these new measurements and estimated TKE budget terms in the context of earlier studies, we first investigate the behavior of each term in the budget after normalization by friction velocity $u_{*}$ and measurement height $z$, as suggested in Monin-Obukhov similarity theory. Here 
friction velocity was defined from longitudinal shear stress, $u_{*}^{2}=-\overline{u^{\prime} w^{\prime}}$.

After normalization of Eq. (1) with friction velocity and measurement height and including a von Kármán constant value $k$ (set equal to 0.4 in the analysis), the governing equation for TKE reads

$$
\begin{aligned}
& \underbrace{\frac{k z}{u_{*}^{3}} \frac{\partial E}{\partial t}}_{\text {Tendency }}=\underbrace{-\frac{k z}{u_{*}} \frac{\partial U}{\partial z}}_{\text {Shear production }}+\underbrace{\frac{k z}{u_{*}^{3}} \frac{g}{\theta} \overline{w^{\prime} \theta_{v}^{\prime}}}_{\text {Buoyancy production }}- \\
& \underbrace{-\frac{k z}{u_{*}^{3}} \frac{\partial \overline{w^{\prime} E^{\prime}}}{\partial z}}_{\text {Turbulent transport }} \underbrace{-\frac{k z}{u_{*}^{3}} \frac{\partial \overline{w^{\prime} p^{\prime} / \rho_{0}}}{\partial z}}_{\text {Pressure transport }} \underbrace{-\frac{k z}{u_{*}^{3}} \epsilon}_{\text {Dissipation }}
\end{aligned}
$$

which can be rewritten in Monin-Obukhov similarity notation:

$$
\begin{aligned}
& \underbrace{\frac{k z}{u_{*}^{3}} \frac{\partial E}{\partial t}}_{\text {Tendency }}=\underbrace{\phi_{m}}_{\text {Shear production }}+\underbrace{\phi_{b}}_{\text {Buoyancy production }}+ \\
& +\underbrace{\phi_{T}}_{\text {Transport }}+\underbrace{\phi_{\epsilon}}_{\text {Dissipation }}
\end{aligned}
$$

Here, we have lumped together pressure and turbulent transport terms into one total transport term $\phi_{\mathrm{T}}$. In Fig. 8, we show the normalized TKE budget terms as a function of the stability parameter $z / L$. Included in the plot are fitted expressions for the budget terms (neglecting the small TKE tendency term).

For buoyancy production, the expression by definition simply reads $-z / L$.

$\phi_{b}=-z / L$

For shear production, we note that a commonly used form of $(1-A z / L)^{b}$ (Stull, 1988) with $A$ equal to 15 and $b$ equal to $1 / 4$ fits the data sufficiently well. However, in neutral conditions our data approach a mean value of about 0.7 rather than 1.0. Our fitted expression thus reads

$\phi_{m}=0.7(1-15 z / L)^{-1 / 4}$.

Normalized shear production was thus found to be low in the present data set in comparison to previously reported results. The scatter in our data was, however, found to be large enough that a von Kármán constant value of 0.4 was found to be within a $95 \%$ confidence interval for neutral stratification. The reason for low normalized shear production is unclear, but it could be a reflection of measurement uncertainty, non-stationarity and heterogeneity.

In Fig. 9, we have replotted the buoyancy production term (in blue circles) and shear production term (in red circles) as

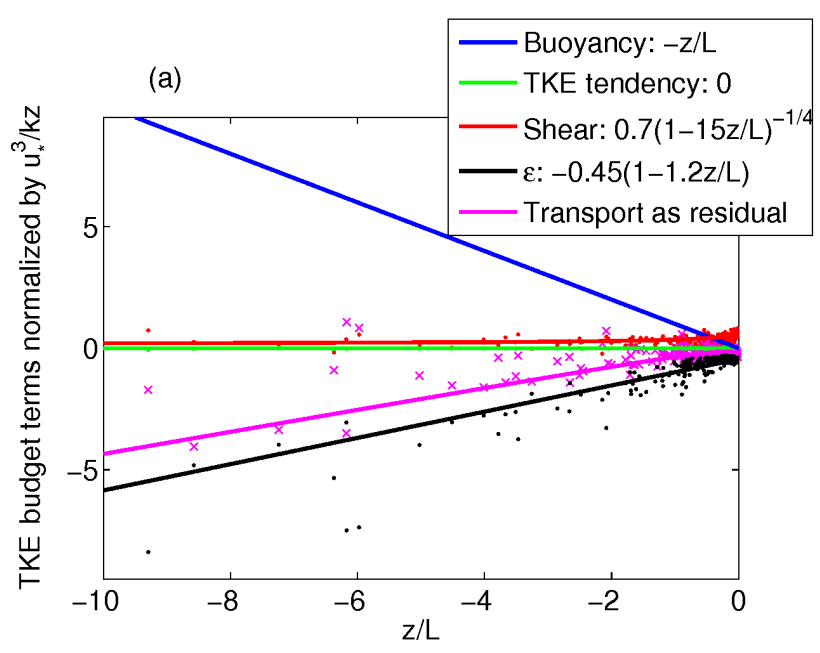

(b)

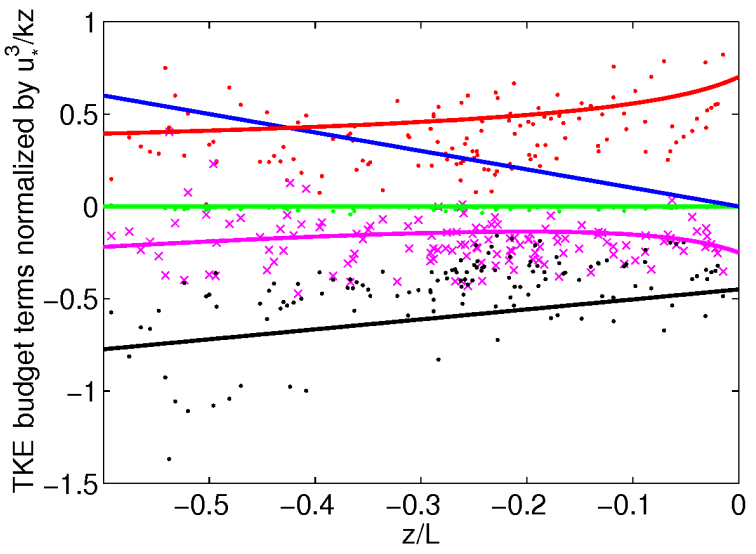

Figure 8. Normalized hourly TKE budget terms for the 10 afternoons shown as a function of the stability parameter $z / L$ in panel (a). A range of -10 to 0 is used on the $x$ axis, and in panel (b) the near-surface data within range of -0.6 to 0 are shown. Data are shown with colored dots and suggested fitted expressions is shown with colored lines: buoyancy production (blue), TKE tendency (green), shear production (red), dissipation (black) and transport (magenta). Two more outlier data values (not shown) were placed at $z / L=-48.2(-37.7)$ with normalized shear production $=0.24,(0.21)$, transport $=-26.3(-20.8)$, dissipation $=-22.1$ $(-17.0)$ and tendency $=0.10(0.05)$.

a function of gradient Richardson number. Here, data outside the afternoon transition period are also included to show the behavior also in slightly stable conditions. Two larger horizontal ellipses encircle data for which the buoyancy production term is very small. An average shear production for this group is about 0.7 as observed for the near-neutral data during the afternoon transition just before stable stratification has started. As discussed in Blay-Carreras et al. (2014b), at this site, there is a delay period between when the buoyancy flux becomes zero and when the vertical virtual potential temperature gradient becomes zero. Therefore, this group of 


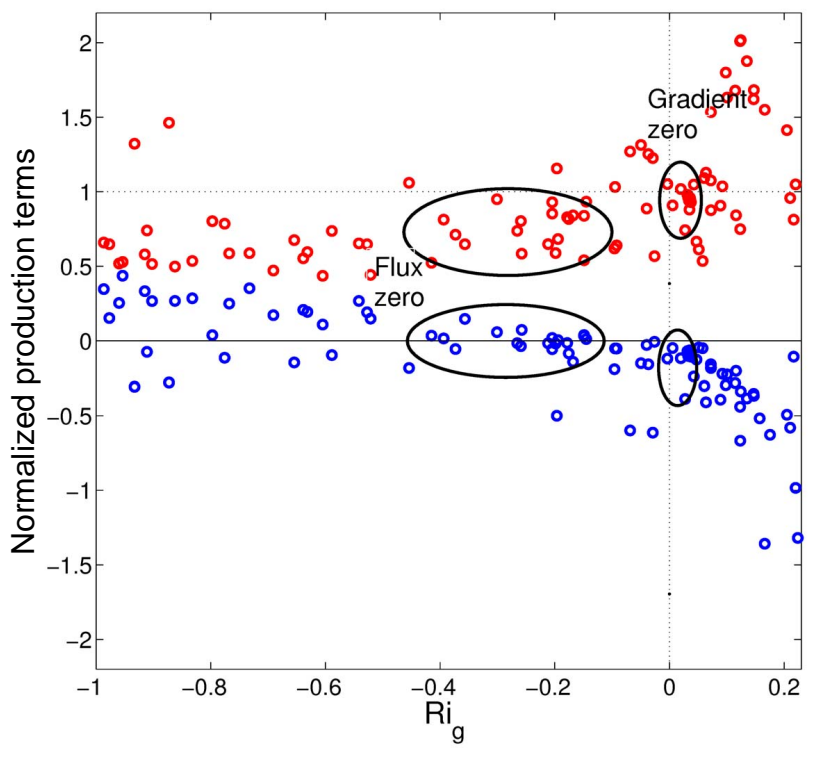

Figure 9. Normalized production terms (buoyancy production = $-z / L$ in blue and shear production in red) for near neutral are shown as a function of Richardson number. Two larger horizontal ellipses encircle some data for which the buoyancy flux is very small, but the Richardson number remains in the range of between about -0.2 and -0.4 , and normalized shear production averages to about 0.7. Two smaller vertical ellipses encircles some data for which both the buoyancy flux is small and Richardson number is small, and normalized shear production averages to about 1.0.

data has a range of Richardson numbers between about -0.4 and -0.2 . Here, Richardson number is the gradient Richardson number, $R i_{\mathrm{g}}=\frac{g \frac{\partial \bar{\theta}}{\partial z}}{\frac{\partial U}{\partial z}}$. This result may, however, not be a general feature of the afternoon and evening transition as discussed by Jensen et al. (2014, 2015), who obtained different results with other data sets. It is interesting to note, however, that for this data set, when the $R i$ number is close to zero and the buoyancy flux is close to zero, such as for the data encircled with the smaller vertical ellipses in Fig. 9, a mean value of shear production of about 1.0 is observed. These observations may be interpreted to imply that, in more stationary neutral conditions (when both flux and gradient are small), we observe the consensus value of 1.0, but in the case of still transitional behavior from convective eddies in the afternoon transition until and around the time of zerobuoyancy flux, we observe lower values of normalized shear production.

For dissipation, we note a variety of different results in the literature (Wyngaard and Coté, 1971; Caughy and Wyngaard, 1979; Frentzen and Vogel, 1992; Albertson et al., 1997; Pahlow et al., 2001). Here, we choose to fit a linear expression to $z / L$. Our fitted expression becomes $\phi_{\epsilon}=0.45(1-1.2 z / L)$,

which suggests a weaker normalized dissipation rate in nearneutral conditions (of about 0.5). Wyngaard and Coté (1971) and Caughy and Wyngaard (1979) find a value of 1.0, which would imply no total transport in neutral conditions (assuming the normalized shear production in neutral conditions is 1). Our value is closer to the value 0.61 suggested by Pahlow et al. (2001) and Albertson et al. (1997), and considering our observed low shear production and measurement uncertainty, these numbers may be considered comparable.

Both our shear production relationship and dissipation relationship was determined by first producing least-squares fitted expressions, but these were slightly adjusted to ensure that the transport data in the TKE budget could also still be reasonably well fitted by a residual expression. For the sum of turbulent and pressure transport term (to be consistent with observed small TKE tendency), our expressions in Eqs. (4)(6) then suggest

$\phi_{\mathrm{T}}=0.46 z / L-0.7(1-15 z / L)^{-1 / 4}+0.45$.

For $z / L$ below -1 , this is approximately a linear equation, $0.5 z / L$, and implies somewhat lower transport than a study focused on this imbalance term by Dupuis et al. (1997), who found a best-fit linear relationship of $0.69 z / L$ using an extensive oceanic data set. In the neutral limit, our fitted value of -0.25 implies a larger transport than suggested by Caughy and Wyngaard (1979) (0.0) and Dupuis et al. (1997) (-0.17) but lower than the value suggested from Albertson et al. (1997) of -0.39 . In a near-neutral range our expression is nonlinear as a consequence of the nonlinearity of the shear production term. A similar nonlinearity is also suggested by the expression given by Caughy and Wyngaard (1979) to come both from shear production and their expression of dissipation rate. In their case, the transport term also becomes positive for a range of near-neutral $z / L$ values. Högström (1990) also observed positive transport values in an extensive data set of near-neutral conditions under steady conditions (not transitions). This was found to be related to a large pressure transport of turbulence into the surface layer which also led to an unusually large normalized dissipation of 1.24 (Högström, 1990). As previously discussed, we only observed a few occasions of positive transport values related to clouds and/or larger uncertainty in the dissipation estimates, and this effect is not included in our mean expression.

\subsection{Alternative parametrization of dissipation including effects of boundary layer height}

An alternative way to express dissipation in models is to relate it to the TKE $(E)$ or subgrid-scale energy $(e)$ and a dissipation length scale $l_{\epsilon}$. For instance, Nadeau et al. (2011) use a relationship of $-2 E^{3 / 2} / z_{i}$ for dissipation corresponding to 

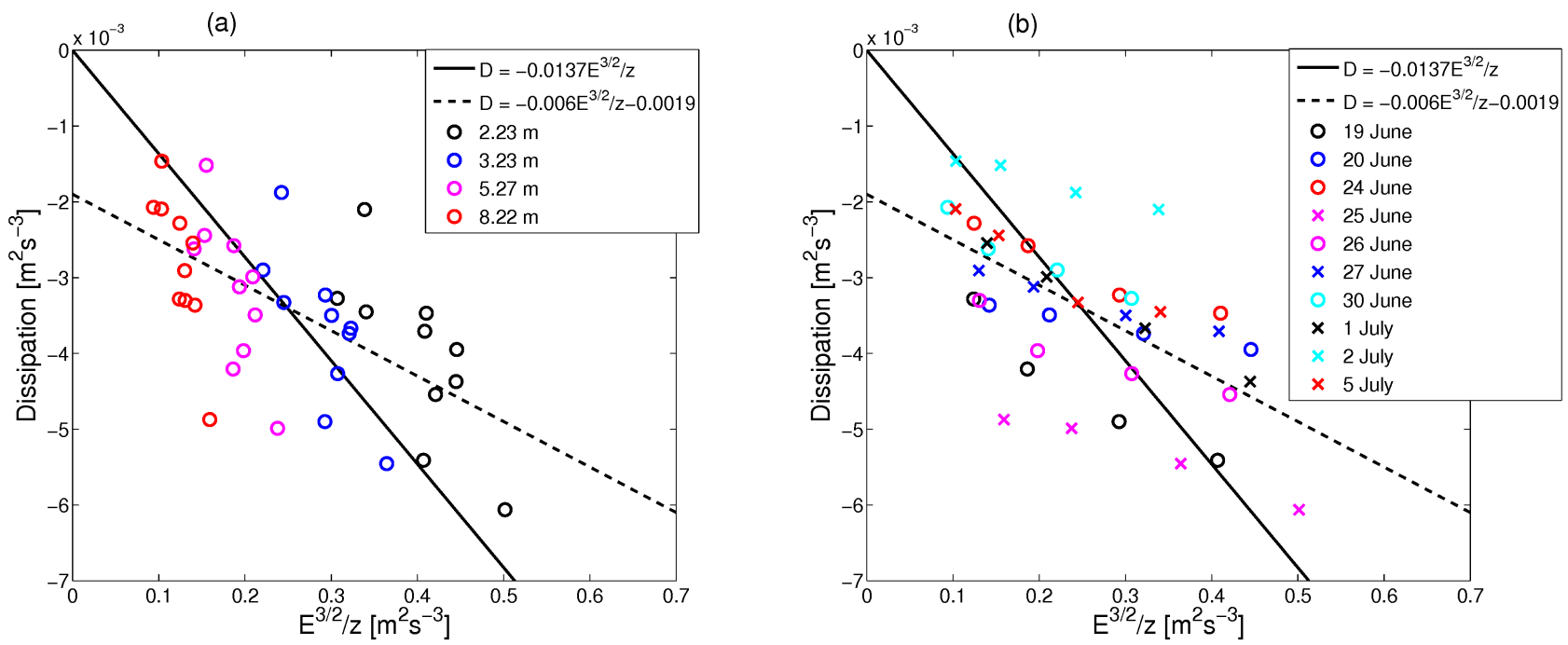

Figure 10. Dissipation is shown as a function of TKE and height near the surface. In panel (a) the four measurement heights 2.23, 3.23, 5.27 and $8.22 \mathrm{~m}$ have been assigned different colors (black, blue, magenta, red). In panel (b), instead, each afternoon has been assigned a different color. Two best-fit linear expressions have also been included. The full line expression assumes that the line goes through origin and the dashed line is without this assumption.

a length scale of $z_{i} / 2$; see also the more generalized case in Moeng and Wyngaard (1989) and their Eq. (2.3). Near the surface, the expectation is that dissipation becomes dependent on the distance above the ground $z$, and we will explore these aspects based on our field measurements.

In Fig. 10, dissipation is shown as a function of $E^{3 / 2} / z$ averaged for the afternoon. Here we first carry out an investigation of the dissipation dependence on measurement height and boundary layer depth using data averaged for full afternoons. Then later we also test our findings using data with a shorter averaging time of $1 \mathrm{~h}$ to be consistent with our hourly TKE budget analysis. The height dependence of the data is displayed in Fig. 10a by assigning different colored circles (black, blue, magenta and red) to the four measurement heights $2.23,3.23,5.27$ and $8.22 \mathrm{~m}$. A higher dissipation rate is found closer to the ground, and at any given measurement level there is a variation in dissipation related to the characteristics of each afternoon. Two best-fit linear relationships are included. One of them (full line) is forced through origin because it may be natural to assume that dissipation is zero when TKE is zero. In Fig. 10b, however, a colored symbol is assigned to each afternoon and it becomes clear that the dissipation dependence on the variable $E^{3 / 2} / z$ is weaker for each afternoon than implied by the full line forced through origin. It is in fact closer to the dependence implied by the dashed line $y=-0.0060 x-0.0019$, which is a best fit on all measurement points. The slope value -0.0060 lies within the 1 standard deviation range of the mean $-0.0044 \pm 0.0017$ that was found when fitting each afternoon independently to the expression $y=k x+A$ and then taking an average of all the fitted slope values $k$. For the intersect values $A$ with the $y$ axis, a mean value of $-0.0023 \mathrm{~m}^{2} \mathrm{~s}^{-3}$ with standard de-

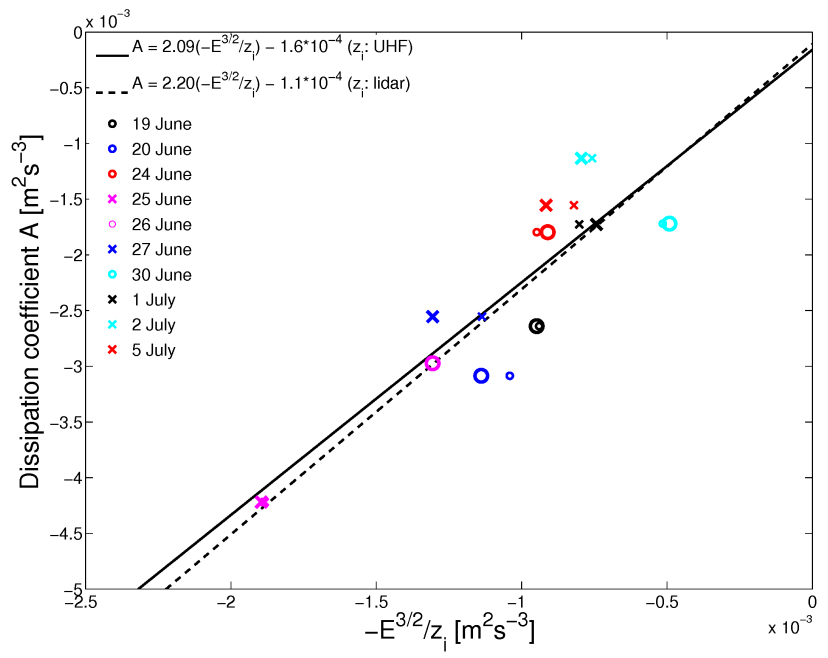

Figure 11. Dissipation coefficient $A$ as a function of mean afternoon TKE and mean afternoon boundary layer height determined from lidar and UHF profiler. Two best-fit linear expressions (full and dashed line) have been included for using the UHF profiler and lidar $z_{i}$ estimates. Large and small symbols correspond to using lidar and UHF profiler data, respectively.

viation $9.3 \times 10^{-4}$ was found by this procedure. Thus, we can conclude with some certainty that non-zero intersection values with the $y$ axis exist in this representation. We interpret this to imply that a variation in dissipation exists which should not be related to height above the surface.

In Fig. 11, we further explore this non-local variation in dissipation by plotting the intersection values $A$ as a function of $-E^{3 / 2} / z_{i}$. Here, mean afternoon TKE values and mean 
(a)

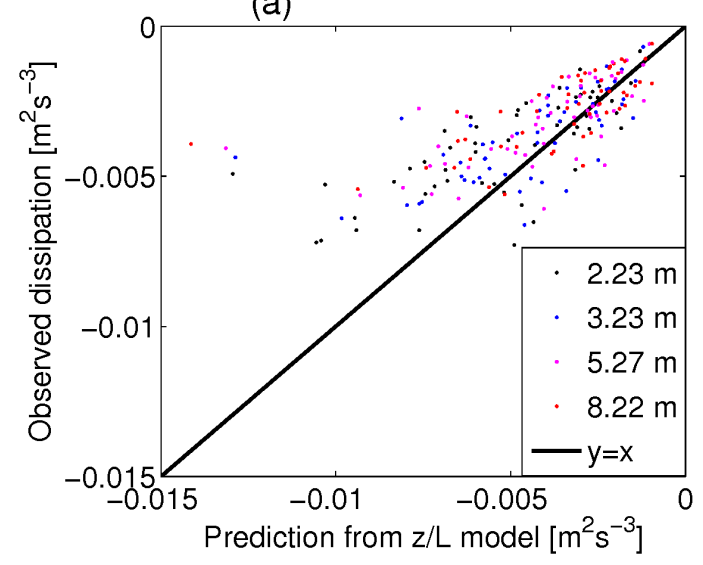

(b)

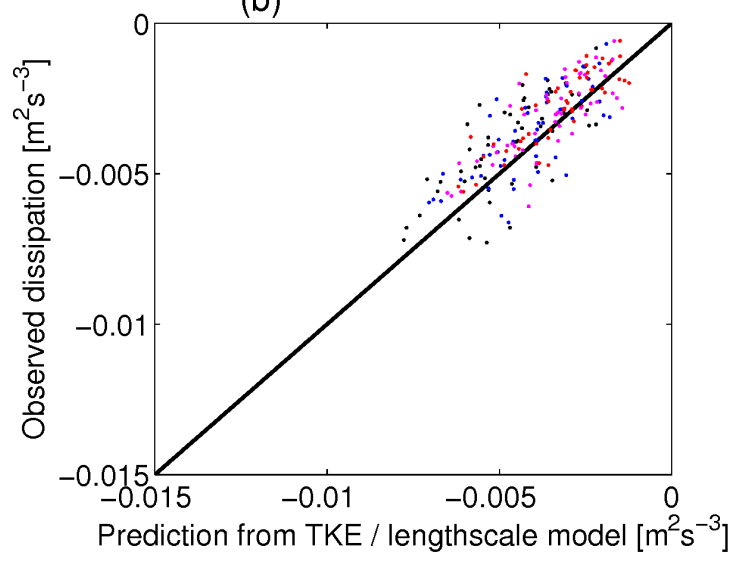

Figure 12. Comparison between observed and predicted dissipation is shown for a model based on $z / L$ in panel (a) and based on TKE and a dissipation length scale taking into account measurement height and boundary layer depth in panel (b). Data shown as black, blue, magenta and red dots denote $2.23,3.23,5.27$ and 8.22 m measurement height, respectively.

boundary layer depth $z_{i}$ determined from lidar and UHF profiler were used. For 26 June no boundary layer height data were available from the lidar. Larger symbols are used to denote when lidar data have been used, and each afternoon is color-coded and uses the same symbols as in previous figures. It can be seen that a positive correlation between the parameters exists, and two best-fit lines are included. The full line based on $z_{i}$ determined from UHF profiler data suggests a slope value of about 2.1 and the dashed line corresponding to lidar data suggests a slope value of 2.2. Both expressions have a small negative intersection value for the $y$ axis of $-1.6 \times 10^{-4}$ and $-1.1 \times 10^{-4} \mathrm{~m}^{2} \mathrm{~s}^{-3}$, respectively, which cannot be concluded to differ much from a value of 0 given the uncertainty in the variables. We note that the slope value of 2.2 corresponds to less deviation from zero of its intersection value with the $y$ axis, and therefore we use this as a slope value representative of the data set.

Our final alternative form for expressing dissipation as a function of TKE and a dissipation length scale then becomes

$D=-\frac{E^{3 / 2}}{l_{\epsilon}}=-E^{3 / 2}\left(\frac{2.2}{z_{i}}+\frac{0.006}{z}\right)$

when combining the fitted slope values in Figs. 10 and 11. Here, the suggestion is that the distance from the ground $z$ and boundary layer depth $z_{i}$ act in parallel to decide the governing dissipation length scale $l_{\epsilon}$. It is worth noting that our coefficient value of 2.2 does not depart very much from the proposed value of 2.0 by Nadeau et al. (2011) or 1.92 by van Driel and Jonker (2011) based on other data sets, suggesting it may have some general validity. Equation (8) also implies that, for heights higher than about $2.73 \%$ of the boundary layer depth, the contribution from the $z$-dependent term is less than $10 \%$ of the $z_{i}$-dependent term. The expression then differs only by about $10 \%$ of what Nadeau et al. (2011) used when modeling dissipation in very convective situations.

Figure 12 shows dissipation estimated from Eq. (8) (in b) and from Eq. (9) (in a):

$D=-\frac{u_{*}^{3}}{k z}(0.45(1-1.2 z / L))$.

Equation (9) is implied by the fitted linear relationship of normalized dissipation to the stability parameter $z / L$ in Eq. (6). In this final evaluation we have used all $53 \mathrm{~h}$ of data during the afternoon transition period for which all required parameters for both models were available. Boundary layer depth estimates from the UHF wind profiler were used to also be able to include data from 26 June.

Both models behave relatively similar for cases with low observed dissipation ( $>-0.0025$ ), whereas the $z / L$ model has a tendency to overestimate dissipation for larger observed values of dissipation and a bias of $-9.3 \times 10^{-4} \mathrm{~m}^{2} \mathrm{~s}^{-3}$ was found. The bias for the TKE-length scale parametrization was $-4.9 \times 10^{-4} \mathrm{~m}^{2} \mathrm{~s}^{-3}$, also suggesting a slight overestimation of dissipation rate. The centered root-mean-square difference was $1.8 \times 10^{-3} \mathrm{~m}^{2} \mathrm{~s}^{-3}$ for the $z / L$ model and about half $\left(0.93 \times 10^{-3} \mathrm{~m}^{2} \mathrm{~s}^{-3}\right)$ for the TKE-length scale model. The linear correlation coefficient between measurement and model was lower for the $z / L$ model $(0.70)$ compared to the TKE-length scale model, which had 0.80. Finally, the standard deviation of the $z / L$ model was found to be $2.5 \times 10^{-3}$ and $1.4 \times 10^{-3} \mathrm{~m}^{2} \mathrm{~s}^{-3}$ for the TKE-length scale model, which should be compared to the observed standard deviation of $1.5 \times 10^{-3} \mathrm{~m}^{2} \mathrm{~s}^{-3}$. In four out of four skill scores the TKE length scale model, which takes into account boundary layer depth and height above the surface, was hence found to better represent the observed dissipation than the stability-dependent $z / L$ model. It should be noted that both models include two fitting parameters and that no explicit 
stability dependence has been included for the TKE length scale model. However, it may be argued that an implicit stability dependence should be included since the magnitude of TKE depends on stability. It should also be recognized that only afternoon data are considered here and other parts of the diurnal cycle such as morning transitions could be studied in future work.

\section{Summary and conclusions}

Using radiosoundings, UHF wind profilers and tower measurements, we summarized an overall description of the prevailing boundary layer situation for 10 intensive observation period (IOP) days. This characterization showed that many different conditions in terms of boundary layer depth, wind speed and moisture conditions occurred on these days, despite being mainly high-pressure fair-weather situations. Some common features are recognized, such as the following:

- Mainly westerly flow above the boundary layer and an easterly or northerly flow in the daytime boundary layer (linked with mountain-plain circulation for most of the days), turning in the evening and nighttime. As the boundary layer flow encounters and mixes with the flow above, a layer of reduced wind speed is also observed for several days.

- Wind direction at a small tower (2-8 m), a taller tower (30-60 m) and the lowest UHF wind profiler level (at $175 \mathrm{~m}$ ) was found to be relatively consistent in daytime and afternoon, but with larger variability in the UHF estimates.

- In the evening, after the buoyancy flux switched sign and stable stratification has begun, the wind direction at the small tower turned rapidly towards south for several of the days related to a shallow drainage flow. At the $60 \mathrm{~m}$ tower and above, a more slow and/or delayed turning was observed which is related to a mountain-plain circulation.

These observations are important to emphasize for a couple of reasons:

- In stable stratification, near-surface TKE budget analysis was concluded to provide very little information about atmospheric conditions above the very nearsurface layers. This is because of decoupling issues, and effects of shallow drainage flow, as well as the mountain-plane circulation related to larger-scale topography and some occasions of nocturnal low-level jets.

- During unstable stratification, in the afternoon transition our surface layer analysis can, however, also be informative of what is occurring above in the mixed layer since the two layers are more closely coupled to each other. The height variation in TKE budget terms could in these conditions be used to also interpret how the mixed layer has an influence on surface layer dynamics.

The afternoon transition was studied using TKE budget analysis. Here, we focused on the slow and persistent changes in TKE budget terms that are well described by an hourly TKE budget analysis, leaving shorter timescales and more temporary fluctuations of TKE for future studies. Several important results were reached:

- All terms of a TKE budget except those of transport could be determined directly from field measurements near the surface on an hourly basis for 10 fair-weather afternoons. This allowed calculation of the total transport as a residual from the other budget terms.

- The TKE tendency term was found to be much smaller than all the other budget terms, suggesting that the surface layer turbulence evolves in a quasi-stationary way during the afternoon transition. Even though TKE tendency was small, we found a relatively high correlation coefficient $(-0.69)$ between mean afternoon TKE tendency and mean afternoon buoyancy production.

- We found that several explanatory factors are needed to be able to interpret the behavior of TKE and TKE tendency during the afternoon transition. Both near-surface wind speed (causing shear production) and buoyancy production of TKE were found to be important production terms at 2-8 $\mathrm{m}$, even though mean afternoon winds were less than $3 \mathrm{~m} \mathrm{~s}^{-1}$ for all days. The shear production term has stronger height dependence than does buoyancy production. Buoyancy therefore becomes more important for the TKE budget with increasing height.

- Larger variations between afternoons were observed in shear production, transport and dissipation compared to buoyancy production. This implies that all these terms are important to take into account of in modeling of sheared convective surface layers.

- A summarizing classification of the 10 IOP afternoons showed that, in general, windier days of the field campaign $(20,25,26$ and 27 June) had a higher transport of TKE out of the near-surface layers as well as often a higher or moderate dissipation of TKE. Afternoons with weaker wind (30 June and 2 July) instead had less transport and weaker dissipation. But, for a more complete picture, buoyancy production, as a key forcing, also needs to be considered (e.g., 19 June), as do variations within the afternoons.

- Normalization of TKE budget terms by friction velocity and measurement height and fitting of empirical ex- 
pressions (Eqs. 4-7) revealed both similarities and differences to earlier studies. Around the time of zerobuoyancy flux, the average of normalized shear production values was about 0.7 (30\% lower than in most findings). In slightly stable stratification with both small buoyancy flux and small virtual potential temperature gradient the mean value of normalized shear production showed the consensus result of 1.0.

- In general, it can be argued that our data suggest that about $50 \%$ of the near-surface production of TKE is locally dissipated, leaving about $50 \%$ available for transport. However, empirically fitted expressions (Eqs. 47) better represent some of the observed subtleties and nonlinear effects of stratification.
- For dissipation we also alternatively proposed a nonlocal parametrization using a TKE-length scale model which takes into account of boundary layer depth and distance above ground. The non-local formulation was found to give a better description of dissipation of TKE and is hence suggested to provide an important component for simple modeling of surface layer TKE, while still taking into account non-local influences. Such modeling is attempted in our companion paper, Part 2. 


\section{Appendix A: Description of boundary layer conditions for 10 IOP days}

\section{A1 19-20 June 2011}

The weather conditions were dominated by a cloud-free high-pressure situation with very few disturbances in incoming shortwave radiation (Nilsson, 2014). A general warming trend was observed from around $12{ }^{\circ} \mathrm{C}$ in the morning of 19 June and reaching about $19^{\circ} \mathrm{C}$ in the afternoon (on the $60 \mathrm{~m}$ tower level). June 20 was warmer, around $20^{\circ} \mathrm{C}$, in the morning and reached about $25^{\circ} \mathrm{C}$ in the afternoon. Relative humidity remained relatively unchanged between the two days, being about $60 \%$ in the morning and decreasing to about $45-$ $50 \%$ in the afternoon before increasing again in the evening.

The boundary layer depth from Fig. 2 shows similar maximum depths of about $1100 \mathrm{~m}$ for the two days, but 19 June has been classified as having a rapid growth and leveling inversion in the late afternoon, whereas 20 June had a more typical growth and leveling inversion (Lothon et al., 2014).

Both days were characterized by moderate westerly winds (higher than about $8 \mathrm{~m} \mathrm{~s}^{-1}$ ) above the boundary layer most of the time (see Figs. A1 and A2). After the time of the evening transition on 20 June at around 19:00 UTC, the greatest upper wind gradient, marked in black, was more diffuse and found to occur mainly around $2000 \mathrm{~m}$. This height marks a dynamical separation of the boundary layer flow with more northerly (19 June) or easterly (20 June) wind from the dominant westerly flow above. Wind speed is (as seen from Figs. A1 and 4) variable in both time and space. At $175 \mathrm{~m}$ (the lowest UHF profiler level) it was around $5 \mathrm{~m} \mathrm{~s}^{-1}$ for a large part of the day and afternoon as well as in the evening on 20 June. As can be seen from Fig. A1, this level is quite representative of the boundary layer flow up to some height where the wind turns, and reduced wind speed is observed. On 19 June, winds were generally lighter in the boundary layer, around $2-3 \mathrm{~m} \mathrm{~s}^{-1}$ at midday and decreasing in the evening.

Wind speed near the surface shows fewer differences between the $60 \mathrm{~m}$ tower (shown in greenish colors) and the small tower (shown in bluish colors) for the two days than at the $175 \mathrm{~m}$ level, which is more representative of the boundary layer flow. Wind direction is reasonably consistent on both towers and the lowest UHF level during the daytime on both days. But once the buoyancy flux becomes negative (marked by a vertical black line in Fig. 3), the wind direction on the small tower shifts rapidly towards south due to a shallow drainage flow. A later and less abrupt turning is observed on the $60 \mathrm{~m}$ tower and the lowest UHF profiler level.

\section{A2 24-27 June 2011}

June 24 may be considered the start of a general warming period which lasted until the evening of 27 June. Temperatures increased from about $11^{\circ} \mathrm{C}$ in the morning of 24 June to about $18^{\circ} \mathrm{C}$ in the afternoon and then only decreased by about $3{ }^{\circ} \mathrm{C}$ until morning of 25 June. The next days had a similar behavior with a maximum temperature of about $24^{\circ} \mathrm{C}$ for 2 June, decreasing by $2{ }^{\circ} \mathrm{C}$ until the morning of the next day (Nilsson, 2014). June 26 later reached a maximum temperature for the time period of about $32^{\circ} \mathrm{C}$. From the afternoon of 26 June the temperature dropped by $6^{\circ} \mathrm{C}$ until the morning of 27 June, which temporarily also reached $32^{\circ} \mathrm{C}$ before midday, before stabilizing at around $30^{\circ} \mathrm{C}$ for a large part of the afternoon.

These days can also be characterized as high-pressure fair-weather situation before the passage of an approaching frontal system reaching the site around 02:00 UTC on 28 June. The cloud cover varied among the days; 24 June had some clouds (mostly cirrus) for most of the day but decreasing amounts in the afternoon from 14:30 UTC. June 25 was completely cloud-free, whereas clouds were observed on 26 June starting around 14:00 UTC. June 27 was cloudfree until the late afternoon, around 16:30 UTC, when some pre-frontal clouds (mainly cirrus) appeared. Relative humidity for the afternoon was about $50-60 \%$ on 24 June (hence comparable to 19 and 20 June) but less for the warmer days: $30-40 \%$ on 25 June, $25-35 \%$ on 26 June and $30-50 \%$ for 27 June. As noted in Lothon et al. (2014), the less typical windier and warmer conditions were related to the presence of a low-pressure area in the lower troposphere over the Gulf of Lion in the Mediterranean Sea.

The maximum boundary layer depth on 24 June was similar to 19 and 20 June $(1100 \mathrm{~m})$ with a more typical growth and leveling behavior. June 25 was also given this classification in Lothon et al. (2014). As can be seen from Fig. 2, the boundary layer depths are, however, lower for the three warmer days of the field campaign, and 26 and 27 June were also classified as having slower boundary layer growth and rapidly decreasing top inversion in the late afternoon. This is in strong contrast to most of the other days. This has been partly explained as a consequence of less sensible heat flux during the warm period (Lothon et al., 2014) and possible effects of subsidence (Pietersen et al., 2015).

June 24 also experienced a strong westerly flow above the boundary layer, as on 19 and 20 June, which, however, became weaker as time progressed, and in the afternoon and evening mainly moderate upper wind gradients (between 0.5 and $1.0 \mathrm{~m} \mathrm{~s}^{-1}$ change in $100 \mathrm{~m}$ ) were observed. The flow in the boundary layer was also weak for 24 June, and wind directions were variably westerly, northwesterly or northerly in the daytime, turning towards easterly and southerly flow in the evening and nighttime. The weaker upper winds above the boundary layer also persisted for 25, 26 and 27 June. For 25 and 26 June there were, however, upper wind speed gradients above $1 \mathrm{~m} \mathrm{~s}^{-1}$ change in $100 \mathrm{~m}$, but these were not always as persistent in time as for 19, 20 June and a large part of 24 June.

For both 25 and 26 June, the boundary layer flow was stronger, with persistent easterly winds turning southerly in nighttime. An average wind speed at $175 \mathrm{~m}$ of about 6- 

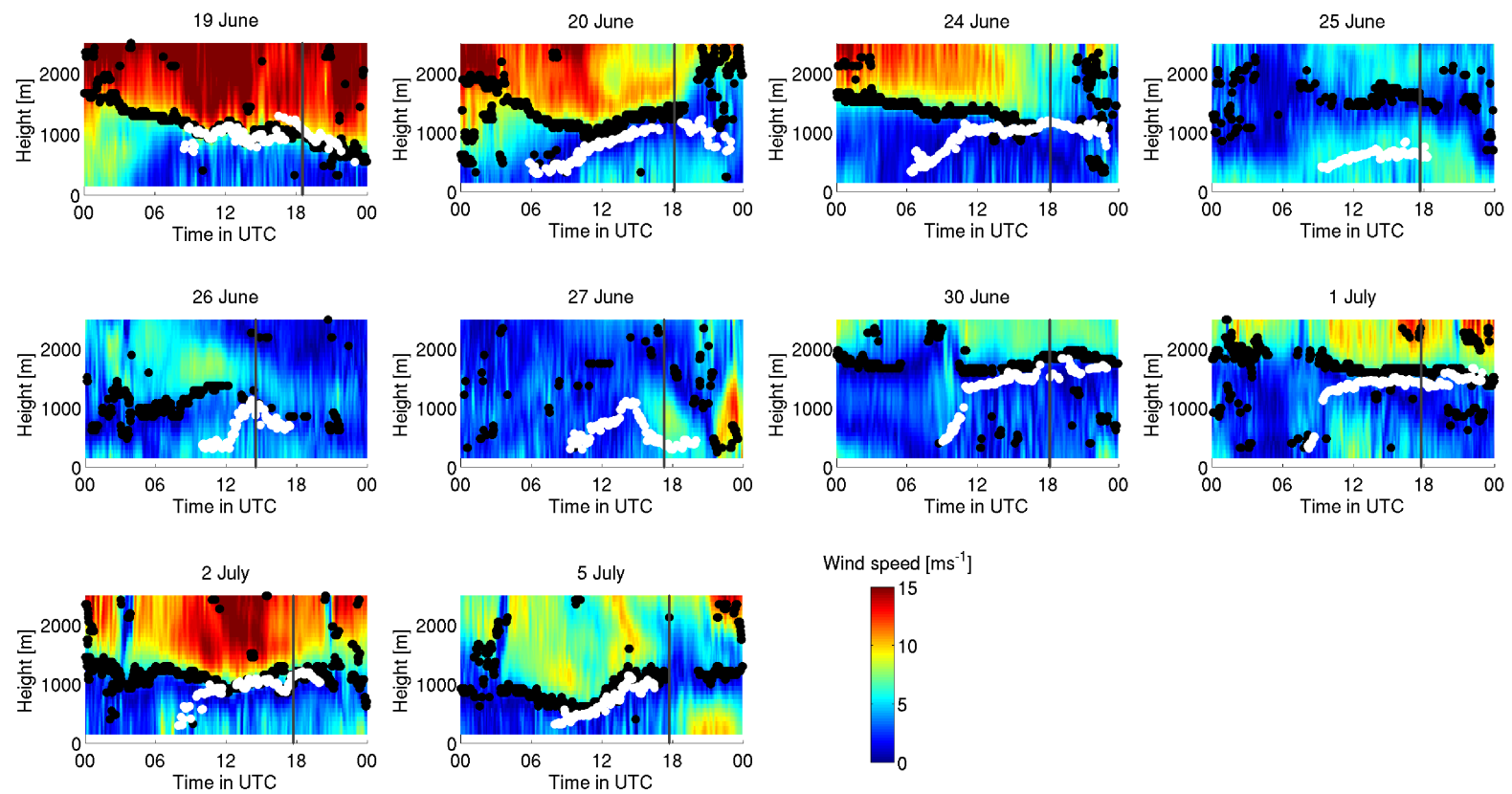

Figure A1. Wind speed from UHF profiler between 175 and $2500 \mathrm{~m}$. Strong local maxima in wind gradient $\left(>1 \mathrm{~m} \mathrm{~s}^{-1}\right.$ change in $\left.100 \mathrm{~m}\right)$ are shown in black. Also shown in white are boundary layer depth estimates from the UHF wind profiler. A vertical line has been included to mark the timing of zero-buoyancy flux at the surface.
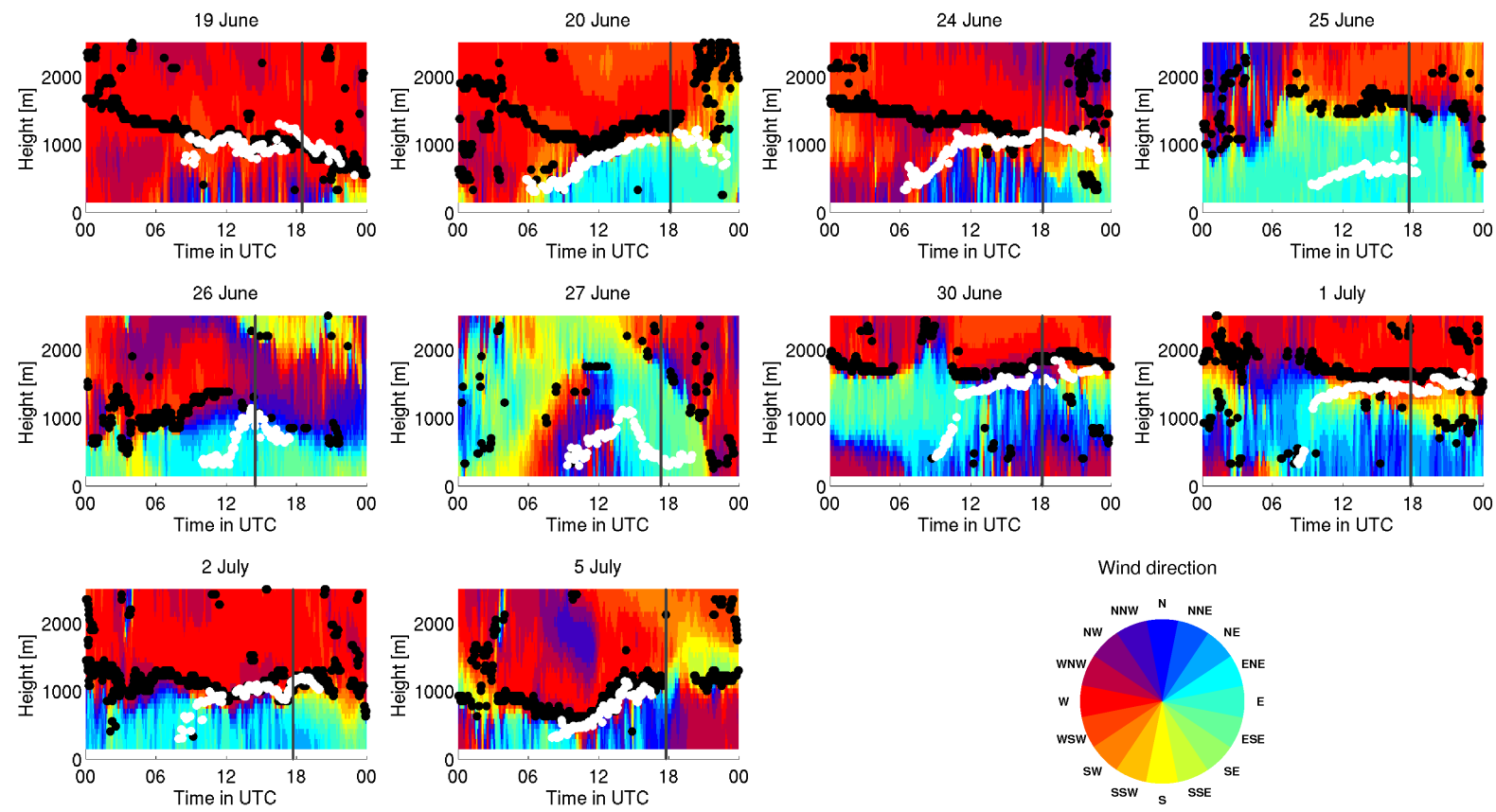

Figure A2. Wind direction from UHF profiler data between 175 and $2500 \mathrm{~m}$. The strongest wind speed gradient identification (black dots) most of the time separates the large-scale westerly flow above from the flow below. During daytime the flow below in the boundary layer is often easterly (or northerly). Also shown in white are the boundary layer depth estimates from the UHF wind profiler. A vertical line has been included to mark the timing of zero-buoyancy flux at surface. 
$7 \mathrm{~m} \mathrm{~s}^{-1}$ for 25 June and $5 \mathrm{~m} \mathrm{~s}^{-1}$ for 26 June makes these two days the overall windiest IOP days studied. For 27 June the wind speed and direction were, as can be seen from Figs. 3 and 4 , more variable. Increasing wind speed from very low in the morning to about $5-6 \mathrm{~m} \mathrm{~s}^{-1}$ as an average for the afternoon and evening at $175 \mathrm{~m}$ was observed. At the same time, the wind direction turned clockwise from northwesterly in the morning to southerly in the evening and westerly in nighttime at the $175 \mathrm{~m}$ level.

\section{A3 30 June and 1-2 July 2011}

June 30 experienced the aftermath of a cold frontal passage that occurred on the previous day and had some stratocumulus clouds in the morning followed by cumulus for most of the day and clearing skies in the evening. Pressure started to rise significantly at midday and during 1 July and also remained relatively high on 2 July (Nilsson, 2014). Both 1 and 2 July were mainly cloud-free except for a short period in the morning of 1 July, and some low stratocumulus started to appear at the end of 2 July. The three days make up another warming period with a similar diurnal cycle with temperatures increasing about 9,8 and $7^{\circ} \mathrm{C}$ in the morning to maximum afternoon values of 19,21 and $24^{\circ} \mathrm{C}$ on 30 June, 1 July and 2 July, respectively. Relative humidity was $50-60 \%$ on 30 June and about 30-40\% for both 1 and 2 July.

On both 30 June and 1 July boundary layer depth was observed to be high, reaching around $1500 \mathrm{~m}$ according to both UHF and radiosounding estimates. On 2 July it was reduced to about $1000 \mathrm{~m}$, comparable to some of the other more typical days of the field campaign. Both 2 July and 30 June were also classified as having a more typical growth and inversion leveling (Lothon et al., 2014), whereas 1 July had a more rapid growth of the boundary layer during the morning explained by a merging of the boundary layer with the residual layer from the previous night (Blay-Carreras et al., 2014a).

June 30 had mainly weak winds in the boundary layer (below $4 \mathrm{~m} \mathrm{~s}^{-1}$ at $175 \mathrm{~m}$ most of the time). Above the high boundary layer depth of $1500 \mathrm{~m}$ there was an upper wind speed gradient with more than $1 \mathrm{~m} \mathrm{~s}^{-1}$ change in $100 \mathrm{~m}$, but winds were also mainly below $7 \mathrm{~m} \mathrm{~s}^{-1}$ above this layer of wind speed increase (and below $2500 \mathrm{~m}$ ). Wind direction in the upper region was mainly from the west as for most days and quite variable in the boundary layer, as can be expected in low-wind conditions. The wind direction stabilized somewhat to mainly northwesterly flow below $500 \mathrm{~m}$ in the evening, after the buoyancy flux turned negative and the wind speed had also increased.

July 1 and especially 2 July had higher wind speed (and still westerly flow) above the boundary layer and mainly easterly (2 July) and northeasterly (1 July) flow in the boundary layer. On both days a change towards south took place in the evening after stable stratification started. This shift of wind direction was slow and delayed and evolving to a full southerly flow at $175 \mathrm{~m}$ later in comparison to the earlier and
Table A1. Near-surface specific humidity from standard radiosoundings $\left[\mathrm{g} \mathrm{kg}^{-1}\right.$ ].

\begin{tabular}{rrrr}
\hline Day & $11: 00$ UTC & $17: 00$ UTC & $23: 00$ UTC \\
\hline 19 June & 5.5 & 6.5 & $8^{\mathrm{a}}$ \\
20 June & 8 & 8 & $12^{\mathrm{a}}$ \\
24 June & 6 & 6 & $7^{\mathrm{a}}$ \\
25 June & 6 & 6 & $9^{\mathrm{a}}$ \\
26 June & 7 & $10^{\mathrm{a}}$ & $10^{\mathrm{a}}$ \\
27 June & 9 & 11 & 14 \\
30 June & 6 & 6 & 8 \\
1 July & 5 & 6 & $8^{\mathrm{a}}$ \\
2 July & 5.5 & 5.5 & $7^{\mathrm{a}}\left({ }^{\mathrm{b}}\right)$ \\
5 July & 7 & 7 & 7 \\
\hline
\end{tabular}

${ }^{a}$ Denotes marked curvature in vertical profile of humidity.

$\mathrm{b}$ Denotes that a sounding at 20:30 UTC was used when no standard radiosounding was available.

more rapid wind direction shifts observed near the surface on the two towers. The change hence started first near the surface and later at higher levels with the onset of a mountainplain circulation.

\section{A4 5 July 2011}

Finally, the last IOP day studied was a completely cloudfree warm day reaching up to $26^{\circ} \mathrm{C}$ around 15:00 UTC with a typical diurnal cycle in temperature but perhaps somewhat more variable relative humidity ranging from 65 to $70 \%$ in the morning down to $30 \%$ at midday, before rising again in the late afternoon and evening. Relative humidity is, of course, affected by the diurnal cycle of temperature, and in fact for 5 July the specific humidity near the surface according to the standard radiosoundings at 11:00, 17:00 and 23:00 UTC (Blay-Carreras, 2013) remained relatively constant at $7 \mathrm{~g} \mathrm{~kg}^{-1}$. Table A1 summarizes specific humidity from these radiosoundings, showing a significant moistening of the near-surface layer at 23:00 UTC compared to midday values for most of the IOP days. Such moistening of near-surface layers has previously been reported by Busse and Knupp (2012) and Bonin et al. (2013). Mahrt (1999) discussed it as being a consequence of a slower decay of latent heat flux than the strength of turbulence and boundary layer depth during evening events. The vertical profile of specific humidity in stable conditions was noted most of the time to have a significant curvature with decreasing moisture at higher levels (Blay-Carreras, 2013).

Boundary layer depth on 5 July was somewhat lower compared to 2 July following a general decreasing trend from the high values observed on 30 June. Potential temperature gradients were often weak especially in the afternoon, making boundary layer depth determination based on strongest gradient below $2500 \mathrm{~m}$ more difficult to use than for some of the other days. UHF estimates nevertheless gave estimates of about $1000 \mathrm{~m}$ as maximum for the afternoon, but with a more 
diffuse top inversion in late afternoon (and a slower growth before midday).

For 5 July the wind speed was again weak in the boundary layer but increased during the late afternoon and evening, and at the same time winds were turning counterclockwise from east or northeasterly flow towards mainly westnorthwesterly. At the same time, the flow just above the boundary layer also turned counterclockwise from west or northwesterly towards southerly flow. The upper winds were mainly weak to moderate $\left(5-11 \mathrm{~m} \mathrm{~s}^{-1}\right)$ and quite variable in time and height.

\section{Appendix B: Afternoon statistics of mean wind speed and TKE budget terms}

In Tables B1 and B2, we report the mean value (and standard deviation) for wind speed, shear production, buoyancy production, transport and dissipation. Table B1 refers to the $2.23 \mathrm{~m}$ level and Table B2 the $8.22 \mathrm{~m}$ level. Note also that a scale factor of $10^{-3}$ has been used for the budget terms.

It is important to note from Tables B1 and B2 that the variation between highest and lowest mean value for the different afternoons for shear production is as large as $6.7 \times$ $10^{-3} \mathrm{~m}^{2} \mathrm{~s}^{-3}$ for the $2 \mathrm{~m}$ level (and $3.5 \times 10^{-3} \mathrm{~m}^{2} \mathrm{~s}^{-3}$ for $8.22 \mathrm{~m}$ level). This can be compared with the buoyancy production variation that is only $1.5(1.4) \times 10^{-3} \mathrm{~m}^{2} \mathrm{~s}^{-3}$ between the different afternoons. As we observed that these two terms are the dominant production terms in the near-surface budget and transport acts as a sink term transporting TKE out of the near-surface layers, we could expect variations in dissipation and transport between different afternoons to be mostly related to variations in shear production this close to the surface. To some extent, the less dominant variations in buoyancy production on different afternoons explain variations in near-surface dissipation (and transport) as already seen from the overall decreasing trend of dissipation rate and buoyancy flux in Fig. 5. This is a main basis for simple modeling attempts of turbulence decay (Nadeau et al., 2011) in convectively dominated conditions. However, our data reveal that the role of shear and transport may be equally important, if not more so, to take into account for modeling of sheared convective surface layers. It is worth commenting on the wind. Although weak (the afternoon mean values are always less than $3 \mathrm{~m} \mathrm{~s}^{-1}$ ), the relative importance of shear is stressed here. The variation between maximum and minimum afternoon mean values for $2.23(8.22) \mathrm{m}$ is as large as $4.4(1.9) \times$ $10^{-3} \mathrm{~m}^{2} \mathrm{~s}^{-3}$ for transport and $4.0(3.5) \times 10^{-3} \mathrm{~m}^{2} \mathrm{~s}^{-3}$ for dissipation. Larger variations in both the transport and dissipation term compared to the buoyancy term are observed for both measurement levels.
In Table B3, we show TKE mean values for the afternoon, early afternoon (between 12:00 and 13:00 UTC) and late afternoon (last $30 \mathrm{~min}$ ), as well as the average TKE tendency for the afternoon. Values are given for both the 2.23 and $8.22 \mathrm{~m}$ level. Comparing TKE mean values and mean wind speed for the afternoon from Tables B1 or B2 shows that the three lowest TKE mean values occurring on 30 June and 2 and 5 July had the lowest wind speed and that 25 June, which had the highest wind speed, also had the highest mean afternoon TKE value. 
Table B1. Afternoon statistics of wind speed, shear production, buoyancy production, transport and dissipation for a measurement height of $2.23 \mathrm{~m}$. Here, the mean value (and standard deviation) for each afternoon period was calculated from the hourly TKE budget results presented in Fig. 5. Note the scale factor of $10^{-3}$ for the TKE budget terms.

\begin{tabular}{rrrrrr}
\hline & $\begin{array}{r}\text { Wind speed } \\
\text { at } 2.23 \mathrm{~m}\end{array}$ & $\begin{array}{r}\text { Shear } \\
\text { production }\end{array}$ & $\begin{array}{r}\text { Buoyancy } \\
\text { production }\end{array}$ & Transport & Dissipation \\
\hline Unit and scale factor & $\mathrm{m} \mathrm{s}^{-1}$ & $10^{-3} \mathrm{~m}^{2} \mathrm{~s}^{-3}$ & $10^{-3} \mathrm{~m}^{2} \mathrm{~s}^{-3}$ & $10^{-3} \mathrm{~m}^{2} \mathrm{~s}^{-3}$ & $10^{-3} \mathrm{~m}^{2} \mathrm{~s}^{-3}$ \\
\hline 19 June & $1.73(0.48)$ & $2.3(0.7)$ & $3.2(1.5)$ & $-0.2(0.7)$ & $-5.4(1.7)$ \\
20 June & $1.96(0.35)$ & $3.8(1.6)$ & $2.9(1.6)$ & $-2.8(1.9)$ & $-4.0(1.3)$ \\
24 June & $1.60(0.54)$ & $2.1(1.1)$ & $3.4(1.7)$ & $-2.1(1.1)$ & $-3.5(0.8)$ \\
25 June & $2.31(0.24)$ & $7.8(1.2)$ & $2.4(1.5)$ & $-4.3(1.7)$ & $-6.1(0.9)$ \\
26 June & $2.12(0.26)$ & $6.9(2.4)$ & $2.1(0.1)$ & $-4.6(1.6)$ & $-4.5(0.9)$ \\
27 June & $2.00(0.50)$ & $4.3(3.2)$ & $1.9(1.1)$ & $-2.5(1.3)$ & $-3.7(0.9)$ \\
30 June & $1.39(0.42)$ & $1.5(1.1)$ & $2.2(1.2)$ & $-0.4(0.7)$ & $-3.3(0.3)$ \\
1 July & $1.75(0.57)$ & $2.6(1.5)$ & $2.8(1.6)$ & $-1.1(0.8)$ & $-4.3(2.4)$ \\
2 July & $1.47(0.53)$ & $1.1(0.6)$ & $2.3(1.4)$ & $-1.2(0.9)$ & $-2.1(0.7)$ \\
5 July & $1.60(0.69)$ & $3.0(4.0)$ & $1.9(1.2)$ & $-1.5(1.8)$ & $-3.4(1.3)$ \\
\hline
\end{tabular}

Table B2. Afternoon statistics of wind speed, shear production, buoyancy production, transport and dissipation for a measurement height of $8.22 \mathrm{~m}$. Here, the mean value (and standard deviation) for each afternoon period was calculated from the hourly TKE budget results presented in Fig. 5. Note the scale factor of $10^{-3}$ for the TKE budget terms.

\begin{tabular}{rrrrrr}
\hline & $\begin{array}{r}\text { Wind speed } \\
\text { at } 8.22 \mathrm{~m}\end{array}$ & $\begin{array}{r}\text { Shear } \\
\text { production }\end{array}$ & $\begin{array}{r}\text { Buoyancy } \\
\text { production }\end{array}$ & Transport & Dissipation \\
\hline Unit and scale factor & $\mathrm{m} \mathrm{s}^{-1}$ & $10^{-3} \mathrm{~m}^{2} \mathrm{~s}^{-3}$ & $10^{-3} \mathrm{~m}^{2} \mathrm{~s}^{-3}$ & $10^{-3} \mathrm{~m}^{2} \mathrm{~s}^{-3}$ & $10^{-3} \mathrm{~m}^{2} \mathrm{~s}^{-3}$ \\
\hline 19 June & $1.97(0.55)$ & $0.5(0.6)$ & $3.2(1.4)$ & $-0.5(0.9)$ & $-3.3(1.2)$ \\
20 June & $2.24(0.38)$ & $2.5(1.1)$ & $3.1(1.8)$ & $-2.3(2.0)$ & $-3.4(1.1)$ \\
24 June & $1.84(0.64)$ & $0.5(0.6)$ & $3.4(1.6)$ & $-1.6(0.9)$ & $-2.3(0.6)$ \\
25 June & $2.75(0.28)$ & $3.7(0.6)$ & $2.5(1.5)$ & $-1.3(1.4)$ & $-4.9(0.7)$ \\
26 June & $2.52(0.30)$ & $3.4(1.4)$ & $2.3(0.4)$ & $-2.5(1.2)$ & $-3.3(0.7)$ \\
27 June & $2.29(0.65)$ & $2.2(1.9)$ & $2.1(1.1)$ & $-1.4(0.6)$ & $-2.9(1.0)$ \\
30 June & $1.61(0.50)$ & $0.5(0.4)$ & $2.2(1.2)$ & $-0.6(0.9)$ & $-2.0(0.2)$ \\
1 July & $2.00(0.68)$ & $0.8(0.5)$ & $2.9(1.3)$ & $-1.1(0.4)$ & $-2.5(1.4)$ \\
2 July & $1.65(0.61)$ & $0.2(0.6)$ & $2.4(1.2)$ & $-1.2(0.9)$ & $-1.5(0.6)$ \\
5 July & $1.83(0.92)$ & $0.9(1.1)$ & $2.0(1.0)$ & $-0.7(0.3)$ & $-2.1(0.7)$ \\
\hline
\end{tabular}


Table B3. Afternoon TKE statistics for the 10 IOP days for measurement heights of 2.23 and $8.22 \mathrm{~m}$. TKE mean values are shown for the afternoon, for early afternoon (between 12:00 and 13:00 UTC) and for the last $30 \mathrm{~min}$ of the afternoon transition. Also shown is the average TKE tendency for each afternoon (note the scale factor of $10^{-5}$ for the column on the right).

\begin{tabular}{|c|c|c|c|c|c|c|c|c|}
\hline \multirow{3}{*}{$\begin{array}{l}\text { Unit and scale factor } \\
\text { Height }\end{array}$} & \multirow{2}{*}{\multicolumn{2}{|c|}{$\begin{array}{l}\text { TKE mean } \\
\text { value for } \\
\text { the afternoon } \\
\mathrm{m}^{2} \mathrm{~s}^{-2}\end{array}$}} & \multirow{2}{*}{\multicolumn{2}{|c|}{$\begin{array}{c}\text { TKE mean value } \\
\text { for the early } \\
\text { afternoon } \\
\text { 12:00-13:00 UTC } \\
\mathrm{m}^{2} \mathrm{~s}^{-2}\end{array}$}} & \multirow{2}{*}{\multicolumn{2}{|c|}{$\begin{array}{c}\text { TKE last } \\
30 \text { min of } \\
\text { the afternoon } \\
\text { transition } \\
\mathrm{m}^{2} \mathrm{~s}^{-2}\end{array}$}} & \multirow{2}{*}{\multicolumn{2}{|c|}{$\begin{array}{c}\begin{array}{c}\text { Average time } \\
\text { rate of } \\
\text { change } \\
\text { of TKE }\end{array} \\
10^{-5} \mathrm{~m}^{2} \mathrm{~s}^{-3}\end{array}$}} \\
\hline & & & & & & & & \\
\hline & $2.23 \mathrm{~m}$ & $8.22 \mathrm{~m}$ & $2.23 \mathrm{~m}$ & $8.22 \mathrm{~m}$ & $2.23 \mathrm{~m}$ & $8.22 \mathrm{~m}$ & $2.23 \mathrm{~m}$ & $8.22 \mathrm{~m}$ \\
\hline 19 June & 0.94 & 1.01 & 1.19 & 1.30 & 0.37 & 0.39 & -4.1 & -4.6 \\
\hline 20 June & 1.00 & 1.11 & 1.10 & 1.19 & 0.57 & 0.70 & -2.6 & -2.5 \\
\hline 24 June & 0.94 & 1.01 & 1.14 & 1.24 & 0.50 & 0.57 & -3.2 & -3.4 \\
\hline 25 June & 1.08 & 1.20 & 1.15 & 1.26 & 0.97 & 1.09 & -1.1 & -1.1 \\
\hline 26 June & 0.96 & 1.05 & 1.02 & 1.12 & 0.89 & 0.96 & -2.5 & -3.0 \\
\hline 27 June & 0.94 & 1.05 & 0.99 & 1.09 & 0.96 & 1.12 & -0.2 & +0.2 \\
\hline 30 June & 0.78 & 0.84 & 0.81 & 0.89 & 0.60 & 0.64 & -1.1 & -1.2 \\
\hline 1 July & 0.99 & 1.10 & 1.24 & 1.35 & 0.69 & 0.74 & -3.4 & -3.7 \\
\hline 2 July & 0.83 & 0.90 & 0.92 & 0.96 & 0.53 & 0.59 & -2.4 & -2.3 \\
\hline 5 July & 0.83 & 0.90 & 1.01 & 1.08 & 0.62 & 0.66 & -2.4 & -2.6 \\
\hline
\end{tabular}


Acknowledgements. The first author thanks ANR for funding this postdoctoral work and would also like to thank Jordi Vilà-Guerau de Arellano, Arnold Moene and Oscar Hartogensis at Wageningen University for fruitful discussions about this work during a research visit in December 2014. The BLLAST field experiment was made possible thanks to the contribution of several institutions and support: INSU-CNRS (Institut National des Sciences de l'Univers, Centre national de la Recherche Scientifique, LEFE-IMAGO program), Météo-France, Observatoire Midi-Pyrénées (University of Toulouse), EUFAR (EUropean Facility for Airborne Research) BLLATE-1 and 2, COST ES0802 (European Cooperation in the Field of Scientific and Technical Research). This research was partially funded by the Office of Naval Research Award \#N00014-11-1-0709, Mountain Terrain Atmospheric Modeling and Observations (MATERHORN) Program. The authors thank Daniel Alexander for providing the technical support for the divergence tower. The field experiment would not have occurred without the contribution of all participating European and American research groups, which all have contributed to a significant extent. The BLLAST field experiment was hosted by the instrumented site of Centre de Recherches Atmosphériques, Lannemezan, France (Observatoire Midi-Pyrénées, Laboratoire d'Aérologie). Its $60 \mathrm{~m}$ tower is partly supported by the POCTEFA/FLUXPYR European program. The authors also thank Yannick Bezombes, Solène Derrien and Frédérique Saïd for their involvement in the measurements used here. Fleur Couvreux and Patrick Augustin are acknowledged for their contribution to the estimates of the PBL depth. BLLAST data are managed by SEDOO, from Observatoire Midi-Pyrénées. See http://bllast.sedoo.fr for all contributions. Since 2013, the French ANR has supported BLLAST analysis.

Edited by: R. J. Beare

Reviewed by: two anonymous referees

\section{References}

Albertson, J., Parlange, M., Kiely, G., and Eichinger, W.: The average dissipation rate of turbulent kinetic energy in the neutral and unstable atmospheric surface layer, J. Geophys. Res., 102, 13423-13432, 1997.

Billesbach, D.: Estimating uncertainties in individual eddy covariance flux measurements: A comparison of methods and a proposed new method, J. Agr. Forest Meteorol., 151, 394-405, 2011.

Blay-Carreras, E.: Day-by-day description of the IOPs, available at: http://bllast.sedoo.fr/documents/Blay-Carreras_ IOPs-description.pdf (last access date: 18 May 2016), 2013.

Blay-Carreras, E., Pino, D., Vilà-Guerau de Arellano, J., van de Boer, A., De Coster, O., Darbieu, C., Hartogensis, O., Lohou, F., Lothon, M., and Pietersen, H.: Role of the residual layer and large-scale subsidence on the development and evolution of the convective boundary layer, Atmos. Chem. Phys., 14, 4515-4530, doi:10.5194/acp-14-4515-2014, 2014a.

Blay-Carreras, E., Pardyjak, E. R., Pino, D., Alexander, D. C., Lohou, F., and Lothon, M.: Countergradient heat flux observations during the evening transition period, Atmos. Chem. Phys., 14, 9077-9085, doi:10.5194/acp-14-9077-2014, 2014b.
BLLAST: Boundary Layer Late Afternoon and Sunset Turbulence (BLLAST) website, available at: http://bllast.sedoo.fr/database/ (last access: 18 May 2016), 2015.

Bonin, T., Chilson, P., Zielke, B., and Fedorovitch, E.: Observations of the Early Evening Boundary-Layer Transition Using a Small Unmanned Aerial System, Bound.-Lay. Meteorol., 146, 119-132, 2013.

Busse, J. and Knupp, K.: Observed Characteristics of the Afternoon-Evening Boundary Layer Transition Based on Sodar and Surface Data, J. Appl. Meteorol. Climatol., 51, 571-582, 2012.

Caughy, S. and Wyngaard, J.: The turbulence kinetic energy budget in convective conditions, Q. J. Roy. Meteor. Soc., 105, 231-239, 1979.

Cohn, S. and Angevine, W.: Boundary Layer Height and Entrainment Zone Thickness Measured by Lidars and Wind-Profiling Radars, J. Appl. Meteor., 39, 1233-1247, 2000.

Darbieu, C., Lohou, F., Lothon, M., Vilà-Guerau de Arellano, J., Couvreux, F., Durand, P., Pino, D., Patton, E. G., Nilsson, E., Blay-Carreras, E., and Gioli, B.: Turbulence vertical structure of the boundary layer during the afternoon transition, Atmos. Chem. Phys., 15, 10071-10086, doi:10.5194/acp-1510071-2015, 2015.

Dupuis, H., Taylor, P. K., Weill, A., and Katsaros, K.: Inertial dissipation method applied to derive turbulent fluxes over the ocean during the Surface of the Ocean, Fluxes and Interactions with the Atmosphere/Atlantic Stratocumulus Transition Experiment (SOFIA/ASTEX) and Structure des Echanges Mer-Atmosphere, Proprietes des Heterogeneites Oceaniques: Recherche Experimentale (SEMAPHORE) experiments with low to moderate wind speeds, J. Geophys. Res., 102, 21115-21129, 1997.

Fedorovich, E. and Conzemius, R.: Effects of wind shear on the atmospheric convective boundary layer structure and evolution, Acta Geophys., 56, 114-141, 2008.

Frentzen, P. and Vogel, C.: The turbulent kinetic energy budget in the atmospheric surface layer: a review and an experimental reexamination in the field, Bound.-Lay. Meteorol., 60, 49-76, 1992.

Garcia, D.: Robust smoothing of gridded data in one and higher dimensions with missing values, Comput. Stat. Data Anal., 54, 1167-1178, 2010.

Goulart, A., Degrazia, G., Rizza, U., and Anfossi, D.: A theoretical model for the study of convective turbulence decay and comparison with large-eddy simulation data, Bound.-Lay. Meteorol., 107, 143-155, 2003.

Goulart, A., Bodmann, B., de Vilhena, M., Soares, P., and Moreira, D.: On the Time Evolution of the Turbulent Kinetic Energy Spectrum for Decaying Turbulence in the Convective Boundary Layer, Bound.-Lay. Meteorol., 138, 61-75, 2010.

Grant, A. L. M.: An observational study of the evening transition boundary-layer, Q. J. Roy. Meteor. Soc., 123, 657-677, 1997.

Högström, U.: Analysis of Turbulence Structure in the Surface layer with a Modified Similarity Formulation for Near Neutral Conditions, J. Atmos. Sci., 47, 1949-1972, 1990.

Högström, U.: Review of some basic characteristics of the atmospheric surface layer, Bound.-Lay. Meteorol., 78, 215-246, 1996.

Jensen, D., Pardyjak, E., and Hoch, S.: Toward understanding surface sensible heat fluxes during transitional stability over contrasting surfaces, in: 21st AMS Symposium on Boundary Layers and Turbulence, 9-13 June 2014, Leeds, United Kingdom, 2014. 
Jensen, D., Nadeu, D., Hoch, S., and Pardyjak, E.: Observations of Near-Surface Heat-Flux and Temperature Profiles Through the Early Evening Transition over Contrasting Surfaces, Bound.Lay. Meteorol., 159, 567-587, doi:10.1007/s10546-015-0067-z, 2015.

Jiménez, M. and Cuxart, J.: A study of the nocturnal flows generated in the north side of the Pyrénées, Atmos. Res., 145-146, 244254,2014

Jiménez, M. and Cuxart, J.: Observed downslope winds during BLLAST'11 and their representation in the MesoNH model, in: Barcelona BLLAST workshop, 2-3 February 2015, Barcelona, Spain, 2015.

Kaimal, J. C. and Finnigan, J. J.: Amospheric Boundary Layer Flows: Their Structure and Measurement, Oxford University Press, New York, 1994.

Kolmogoroff, A.: Local structure of turbulence in an incompressible viscous fluid at very high Reynolds numbers, Dokl. Akad. Nauk SSSR, 30, 299-303, 1941.

Kumar, V., Kleissl, J., Meneveau, C., and Parlange, M.: Large eddy simulation of a diurnal cycle of the atmospheric boundary layer: Atmospheric stability and scaling issues, Water Resour. Res., 42, 3-18, 2006.

Lothon, M., Lohou, F., Pino, D., Couvreux, F., Pardyjak, E. R., Reuder, J., Vilà-Guerau de Arellano, J., Durand, P., Hartogensis, O., Legain, D., Augustin, P., Gioli, B., Lenschow, D. H., Faloona, I., Yagüe, C., Alexander, D. C., Angevine, W. M., Bargain, E., Barrié, J., Bazile, E., Bezombes, Y., Blay-Carreras, E., van de Boer, A., Boichard, J. L., Bourdon, A., Butet, A., Campistron, B., de Coster, O., Cuxart, J., Dabas, A., Darbieu, C., Deboudt, K., Delbarre, H., Derrien, S., Flament, P., Fourmentin, M., Garai, A., Gibert, F., Graf, A., Groebner, J., Guichard, F., Jiménez, M. A., Jonassen, M., van den Kroonenberg, A., Magliulo, V., Martin, S., Martinez, D., Mastrorillo, L., Moene, A. F., Molinos, F., Moulin, E., Pietersen, H. P., Piguet, B., Pique, E., RománCascón, C., Rufin-Soler, C., Saïd, F., Sastre-Marugán, M., Seity, Y., Steeneveld, G. J., Toscano, P., Traullé, O., Tzanos, D., Wacker, S., Wildmann, N., and Zaldei, A.: The BLLAST field experiment: Boundary-Layer Late Afternoon and Sunset Turbulence, Atmos. Chem. Phys., 14, 10931-10960, doi:10.5194/acp14-10931-2014, 2014.

Mahrt, L.: Stratified atmospheric boundary layers, Bound.-Lay. Meteorol., 90, 375-396, 1999.

Moeng, C.-H. and Sullivan, P. P.: A comparison of shear and buoyancy driven planetary-boundary-layer flows, J. Atmos. Sci., 51, 999-1022, 1994.

Moeng, C.-H. and Wyngaard, J.: Evaluation of Turbulent Transport and Dissipation Closures in Second-Order Modeling, J. Atmos. Sci., 46, 2311-2330, 1989.

Nadeau, D. F., Pardyjak, E. R., Higgins, C. W., Fernando, H. J. S., and Parlange, M. B.: A simple model for the afternoon and early evening decay of convective turbulence over different land surfaces, Bound.-Lay. Meteorol., 141, 301-324, 2011.

Nauta, L.: Shallow Drainage Flows over Light Sloping Terrain during BLLAST 2011: Two Case Studies, Master's thesis, Wageningen University, Wageningen, the Netherlands, 2013.

Nieuwstadt, F. T. M. and Brost, R. A.: The decay of convective turbulence, J. Atmos. Sci., 43, 532-546, 1986.

Nilsson, E.: Day-by-day analysis of synoptic and meteorological conditions, available at: http://bllast.sedoo.fr/documents/
Synoptic_BLLAST_ECMWF_and_IR_low_winds_fisheye_ surface_obs_radiation_60mbasic_60mtempRH.pdf (last access: 18 May 2016), 2014.

Nilsson, E., Lothon, M., Lohou, F., Pardyjak, E., Hartogensis, O., and Darbieu, C.: Turbulence kinetic energy budget during the afternoon transition - Part 2: A simple TKE model, Atmos. Chem Phys., 16, 8873-8898, doi:10.5194/acp-16-8873-2016, 2016.

Pahlow, M., Parlange, M., and Porté-Agel, F.: On Monin-Obukhov Similarity in the Stable Atmospheric Boundary Layer, Bound.Lay. Meteorol., 99, 225-248, 2001.

Pietersen, H. P., Vilà-Guerau de Arellano, J., Augustin, P., van de Boer, A., de Coster, O., Delbarre, H., Durand, P., Fourmentin, M., Gioli, B., Hartogensis, O., Lohou, F., Lothon, M., Ouwersloot, H. G., Pino, D., and Reuder, J.: Study of a prototypical convective boundary layer observed during BLLAST: contributions by large-scale forcings, Atmos. Chem. Phys., 15, 42414257, doi:10.5194/acp-15-4241-2015, 2015.

Pino, D., Vilà-Guerau de Arellano, J., and Duynkerke, P.: The contribution of shear to the evolution of a convective boundary layer, J. Atmos. Sci., 60, 1913-1926, 2003.

Pino, D., Jonker, H. J. J., Vilà de Arellano, J., and Dosio, A.: Role of shear and the inversion strength during sunset turbulence over land: characteristic length scales, Bound.-Lay. Meteorol., 121, 537-556, 2006.

Puhales, F., Rizza, U., Degrazia, G., and Acevedo, O.: A simple parameterization for the turbulent kinetic energy transport terms in the convective boundary layer derived from large eddy simulation, Physica A, 392, 583-595, 2013.

Rizza, U., Miglietta, M., Degrazia, G., Acevedo, O., and Marques, E.: Sunset decay of the convective turbulence with Large-Eddy Simulation under realistic conditions, Physica A, 392, 44814490, 2013.

Román-Cascón, C., Yague, C., Mahrt, L., Sastre, M., Steeneveld, G.-J., Pardyjak, E., and van de Boer, A.: Interactions among Drainage flows, Gravity waves and Turbulence: 2nd July, in: Barcelona BLLAST workshop, 2-3 February 2015, Barcelona, Spain, 2015.

Said, F., Donier, J., Campistron, B., Bezombes, Y., Bousquet, O., Derrien, S. Douffet, T., and Garrouste, O.: CNRM and CRA UHF profilers Site 1 and 2: 15 June-5 July 2011, Internal report 2012/1, Tech. rep., 2012.

Stull, R. B.: An Introduction to Boundary Layer Meteorology, Kluwer Academic Publishers, Dordrecht, The Netherlands, 1988.

Taylor, A., Beare, R., and Thomson, D.: Simulating Dispersion in the Evening-Transition Boundary Layer, Bound.-Lay. Meteorol., 153, 389-407, 2014.

van Driel, R. and Jonker, H. J. J.: Convective boundary layers driven by nonstationary surface heat fluxes, J. Atmos. Sci., 68, 727-738, 2011.

Wingo, S. M. and Knupp, K. R.: Multi-platform observations characterizing the afternoon-to-evening transition of the planetary boundary layer in northern Alabama, USA, Bound.-Lay. Meteorol., 155, 29-53, 2015.

Wyngaard, J. C. and Coté, O. R.: The Budgets of Turbulent Kinetic Energy and Temperature Variance in the Atmospheric Surface Layer, J. Atmos. Sci., 28, 190-201, 1971. 